\title{
Safety of Topical Non-steroidal Anti-Inflammatory Drugs in Osteoarthritis: Outcomes of a Systematic Review and Meta-Analysis
}

\author{
Germain Honvo $^{1,2}$ (D) . Victoria Leclercq ${ }^{1,2} \cdot$ Anton Geerinck $^{1,2} \cdot$ Thierry Thomas $^{3} \cdot$ Nicola Veronese $^{4} \cdot$ Alexia Charles $^{1,2}$. \\ Véronique Rabenda $^{1,2} \cdot$ Charlotte Beaudart ${ }^{1,2} \cdot$ Cyrus Cooper $^{2,5,6} \cdot$ Jean-Yves Reginster ${ }^{1,2,7}$ (D) Olivier Bruyère $^{1,2}$ (D)
}

(c) The Author(s) 2019

\begin{abstract} and subcutaneous tissue, musculoskeletal and connective tissue. topical NSAIDs and placebo (OR 0.96, 95\% CI 0.73-1.27). with other anti-OA treatments.

\section{Introduction}

Osteoarthritis (OA) is a progressive, degenerative disorder, commonly affecting hand, knee and hip joints and causing considerable pain and disability, as well as reduced quality of life [1]. The incidence of OA is rising due to the aging population and the increase in obesity [1]. Topical non-steroidal anti-inflammatory drugs (NSAIDs) are widely recommended in national and international guidelines as an early option for the symptomatic management of OA [2-6]. For
\end{abstract}

Objective We aimed to assess the safety of topical non-steroidal anti-inflammatory drugs (NSAIDs) in the management of osteoarthritis (OA) in a systematic review and meta-analysis of randomized, placebo-controlled trials.

Methods A comprehensive literature search was undertaken in the MEDLINE, Cochrane Central Register of Controlled Trials (CENTRAL), and Scopus electronic databases. Randomized, double-blind, placebo-controlled, parallel-group trials that assessed adverse events (AEs) with topical NSAIDs in patients with OA were eligible for inclusion. Authors and/or study sponsors were contacted to obtain the full report of AEs. The primary outcomes were overall severe and serious AEs, as well as the following MedDRA System Organ Class (SOC)-related AEs: gastrointestinal, vascular, cardiac, nervous system, skin

Results The search strategy identified 1209 records, from which 25 papers were included in the qualitative synthesis and 19 were included in the meta-analysis, after exclusions. Overall, more total AEs (odds ratio [OR] 1.16, 95\% confidence interval $[\mathrm{CI}] 1.04-1.29 ; I^{2}=0.0 \%$ ) and more withdrawals due to AEs (OR $1.49,95 \%$ CI $1.15-1.92 ; I^{2}=0.0 \%$ ) were observed with topical NSAIDs compared with placebo. The same results were achieved with topical diclofenac, largely driven by an increase in skin and subcutaneous tissue disorders (OR 1.73, 95\% CI 0.96-3.10), although the difference was not statistically significant compared with placebo. No significant difference in the odds for gastrointestinal disorders was observed between

Conclusions Topical NSAIDs may be considered safe in the management of OA, especially with regard to low gastrointestinal toxicity. The use of topical NSAIDs in OA should be considered, taking into account their risk: benefit profile in comparison

Electronic supplementary material The online version of this article (https://doi.org/10.1007/s40266-019-00661-0) contains supplementary material, which is available to authorized users.

Germain Honvo

germain.honvo@uliege.be

Extended author information available on the last page of the article

\section{Key Points}

This comprehensive literature review and meta-analysis provides convincing evidence that topical non-steroidal anti-inflammatory drugs (NSAIDs) may be considered safe to use in the early treatment of OA.

The safety profile of topical NSAIDs is shown to be similar to that of placebo in randomized controlled trials; of particular importance is the low gastrointestinal toxicity, which makes the topical route preferable to oral administration.

Topical NSAIDs offer a favourable risk: benefit profile and may be safely used in combination with other treatment strategies for optimal management of OA. 
example, the European Society for Clinical and Economic Aspects of Osteoporosis, Osteoarthritis and Musculoskeletal Diseases (ESCEO) recommends topical NSAIDs as a step 1 pharmacological therapy for the management of knee OA [2], and the American College of Rheumatology (ACR) recommends topical NSAIDs for the initial management of hand or knee OA [4]. In addition, the ACR recommends that people aged $\geq 75$ years should use topical rather than oral NSAIDs; older patients often have comorbidities and/ or an increased risk of cardiovascular, gastrointestinal (GI) or renal adverse events (AEs) [4].

Topical NSAIDs are generally recommended ahead of oral NSAIDs or opioids for pain relief due to their superior safety profile. Topical NSAIDs have a small to moderate effect on pain in hip and knee OA, with effect size measured as 0.44 (95\% confidence interval [CI] 0.27-0.62) [7]. In fact, the efficacy of topical NSAIDs is similar to that of oral NSAIDs but with a better safety profile due to lower systemic absorption [8]. Topical NSAIDs are associated with a lower risk of GI AEs and a higher risk of dermatological AEs compared with oral NSAIDs [8]. A systematic literature review of 16 randomized controlled trials (RCTs; with placebo and/or an active control) and 3 observational studies in older adults with OA found that while topical NSAIDs were associated with some safety issues, they were safer than oral NSAIDs. Based on data from the included RCTs, up to $39 \%$ of patients using a topical NSAID reported an application site $\mathrm{AE}$, compared with $25 \%$ of patients receiving a vehicle or placebo. Likewise, up to $21 \%$ of patients using topical NSAIDs withdrew from the trials due to AEs, compared with $16 \%$ of those receiving placebo. This review also found that a substantial proportion of patients reported systemic AEs with topical NSAIDs, compared with placebo [9]. More recent Cochrane meta-analyses found that topical NSAIDs were significantly more effective than placebo for reducing pain due to chronic musculoskeletal conditions (largely from trials in patients with knee OA), with an increase in local AEs (mostly mild skin reactions) for diclofenac compared with placebo, but no increase for topical ketoprofen and no increase in serious AEs [10,11].

To date, few meta-analyses have assessed the efficacy and safety of topical NSAIDs [10, 12, 13]. Those that have assessed safety used only published data, and it is well known that safety data are often underreported in manuscripts. The objective of this study was to assess the safety of topical NSAIDs in the management of OA in a systematic review and meta-analysis of randomized, placebo-controlled trials. In order to better estimate the safety profile of these OA medications, the authors of the manuscripts and/or the sponsors of the studies were contacted to obtain the full report of AEs.

\section{Methods}

The protocol of this systematic review and meta-analysis was previously registered in the PROSPERO database (registration number CRD42017058509). The systematic review was performed in accordance with the recommendations in the Cochrane Handbook for Systematic Reviews of Interventions [14], and the findings were reported according to the Preferred Reporting Items for Systematic Reviews and Meta-Analyses (PRISMA) guidelines [15]. The entire review process (study selection and risk of bias assessment) was undertaken using Covidence, the Cochrane platform for systematic reviews.

\subsection{Eligibility Criteria}

Randomized, double-blind, placebo-controlled, parallelgroup trials that have assessed the AEs associated with topical NSAIDs in patients with OA were eligible for inclusion in this meta-analysis. The following studies were excluded: crossover studies, reviews or meta-analyses, letters, comments or editorials. Studies that allowed concomitant antiOA medications during the trial (other than rescue medication such as paracetamol or aspirin) were also excluded, as were trials involving animal.

\subsection{Data Sources and Search Strategies}

A comprehensive literature search was undertaken in the MEDLINE (via Ovid), Cochrane Central Register of Controlled Trials (Ovid CENTRAL) and Scopus electronic databases. Each database was searched from inception until 1 August 2017. We searched for randomized, placebo-controlled trials of topical NSAIDs in OA, using a combination of study design-, treatment-, and disease-specific key words and/or Medical Subject Heading (MeSH) terms. While AEs were the outcomes of interest for this study, we decided to avoid the outcome-specific keywords in the search strategies because of the possibility that a study on the efficacy of a drug may have not mentioned terms related to AEs in its title, abstract or in the keywords sections. The search was limited to English and French publications and to human subjects. Detailed search strategies for the MEDLINE/CENTRAL and Scopus databases are reported in the Electronic Supplementary Material (ESM) 1.

Two clinical trials registries, ClinicalTrials.gov (clinicaltrials.gov/) and the World Health Organization's International Clinical Trials Registry Platform Search portal (apps. who.int/trialsearch/), were also checked for trial results that would not have been published. Finally, very recent metaanalyses were also screened for any additional relevant studies. For all studies that responded to the selection criteria, 
the authors of the manuscripts and/or the sponsors of the studies were automatically contacted to obtain the full report of AEs, as long as there was some way to contact them (email, fax, telephone number, or co-author's email in other articles).

We set up search alerts in the bibliographic databases for any new relevant RCTs that were published from 1 August 2017 to 30 September 2018.

\subsection{Study Selection and Data Extraction}

Two members of the review team (GH and VL) independently evaluated each title and abstract to exclude only obvious irrelevant studies, according to the predefined eligibility criteria. At this stage, the criteria related to adverse effects was not considered for selection as studies focusing on the efficacy of a treatment may not report data about adverse effects in the abstract, meaning that all trials mentioning only the efficacy information were retrieved at this stage. After this first step, the two investigators independently reviewed each of the full-texts of the articles not excluded during the initial screening stage, to determine whether the studies met all the selection criteria. Those that did not meet these criteria were definitely excluded. All differences of opinion regarding the selection of articles were resolved through discussion and consensus between the two investigators; any persistent disagreement was solved with the intervention of another member of the review team (VR). A flowchart of the number of included studies at each step was established, including the reasons for excluding studies during the full-text reading process.

The full-texts of the selected studies were screened for extraction of relevant data, using a standard data extraction form. Outcome results data were independently extracted by two members of the review team (GH and VL). For each study, the following data were extracted: characteristics of the manuscript, characteristics of the trial, objective and design of the study, characteristics of the patients, characteristics of the disease, characteristics of the treatments, AEs (outcomes) reported during the trial, and the main conclusion of the study. The raw data (number of events in each group) were extracted for each outcome. The number of patients who experienced any body system-related AE at least once (e.g. nervous system, GI system), as well as specific AEs within each body system (e.g. headache, abdominal pain), were extracted. As much as possible, data from the intention-to-treat (ITT) analysis were considered.

\subsection{Assessment of Risk of Bias in the Included Studies}

Two authors of the review team (GH and VL) independently assessed the risk of bias in each study using the Cochrane Collaboration's tool for risk of bias assessment [14]. The following characteristics were evaluated:

- Random sequence generation: We assessed whether the allocation sequence was adequately generated.

- Allocation concealment: We assessed the method used to conceal the allocation sequence, evaluating whether the intervention allocation could have been foreseen in advance.

- Blinding of participants and personnel: We assessed the method used to blind study participants and personnel from knowledge of which intervention a participant received and whether the intended blinding was effective.

- Blinding of outcome assessment: We assessed the method used to blind outcome assessors from knowledge of which intervention a participant received and whether the intended blinding was effective.

- Incomplete outcome data: We assessed whether participants' exclusions, attrition and incomplete outcome data were adequately addressed in the paper.

- Selective outcomes reporting: We checked whether there was evidence of selective reporting of AEs.

Each of these items was either categorized as 'low risk of bias', 'high risk of bias', or 'unclear risk of bias'. 'Low risk of bias' or 'high risk of bias' was attributed for an item when there was sufficient information in the manuscript to judge the risk of bias as 'low' or 'high', otherwise 'unclear risk of bias' was attributed to the item. Disagreements were solved by discussion between the two reviewers during a consensus meeting, and involved, when necessary, another member of the review team (VR or AG) for final decision.

\subsection{Outcomes of Interest}

The main System Organ Classes (SOCs) that are likely to be affected by the use of topical NSAIDs in the treatment of OA were explored in this meta-analysis.

The following Medical Dictionary for Regulatory Activities (MedDRA) SOC-related AEs were defined as primary outcomes: GI, vascular, cardiac, nervous system, skin and subcutaneous tissue, and musculoskeletal and connective tissue, along with overall severe and serious AEs. Secondary outcomes were withdrawals due to AEs (i.e. the number of participants who stopped the treatment due to an AE), and total number of AEs (i.e. the number of patients who experienced any $\mathrm{AE}$ at least once). 


\subsection{Data Analysis}

Analyses were performed using STATA 14.2 software. We described harms associated with the treatment as odds ratio (OR) with $95 \% \mathrm{CI}$, and computed an overall effect size for each primary or secondary outcome (AE). Anticipating substantial variability among trial results (i.e. the interstudy variability), we assumed heterogeneity in the occurrence of the AEs; thus, we planned to use random-effects models for the meta-analyses. We estimated the overall effects and heterogeneity using the DerSimonian and Laird random-effects model [16]. As this method provides biased estimate of the between-study variance with sparse events [17, 18], we also performed the meta-analyses using the restricted maximum likelihood (REML) method [19]. We reported only the results from the DerSimonian and Laird random-effects model as we found no difference in the effects computed by the two methods. We preferred reporting the results from the DerSimonian and Laird method (which uses a correction factor) because it allows for displaying studies with null event on the forest plot, even if those with a null event in both the intervention and control groups are excluded from the overall effect size computation. On the contrary, with the REML method, these studies are not displayed on the forest plot.

We tested heterogeneity using the Cochran's $Q$ test. As we were performing a random-effects meta-analysis, we used the Tau-squared $\left(\mathrm{Tau}^{2}\right)$ estimate as the measure of the between-study variance. The $I$-squared $\left(I^{2}\right)$ statistic was used to quantify heterogeneity, measuring the percentage of total variation across studies due to heterogeneity [20]. In the case of substantial heterogeneity, we prespecified to undertake subgroup analyses, stratifying the analyses according to participants' age in the intervention group, duration of the OA complaint, location of OA (knee, hand, hip), number of joints treated, formulation regimen of the treatment (cream, solution), drug dose, duration of the trial, nature of the comparator (placebo vs. carrier), and risk of bias in the studies (e.g. studies with a low risk of bias vs. all other studies).

We assessed funnel plot asymmetry for publication bias by visual inspection and using the Harbord test [21], which is more suitable for dichotomous outcomes, with effect sizes measured as OR [22], than the classical Egger's test [23]. Finally, the certainty of each evidence was assessed using the Grading of Recommendations Assessment, Development and Evaluation (GRADE) approach [24], and a table summarizing the findings was prepared using the GRADEpro online software [25].

\section{Results}

Database searches initially identified 1206 records; one additional article was identified by a manual search in MEDLINE, and data for two trials were provided by a pharmaceutical company (GlaxoSmithKline [GSK]). In fact, the two trials were referenced on ClinicalTrials.gov, but their results were only published in combination with the results of other trials as a post hoc analysis and pooled analysis [26, 27]. Consequently, these publications could not be included since they were assimilated to meta-analyses. However, GSK supplied us with the raw data for each of these two trials and we subsequently included them after evaluation against our selection criteria.

After exclusions based on titles and abstracts, 58 articles were screened in full against the selection criteria, with a further 33 studies being excluded for various reasons (Fig. 1). Twenty-five papers were included in the qualitative synthesis, and 19 studies with adequate data were ultimately included in the meta-analysis: 8 RCTs of diclofenac, 4 with ketoprofen, 3 with ibuprofen, and 1 study each on eltenac, piroxicam, nimesulide and S-flurbiprofen [28-50].

Table 1 presents the characteristics of the studies included through the systematic review process (those included in the quantitative synthesis [meta-analysis] are highlighted). Most of the studies included patients with knee OA; only two studies were conducted in patients with hand OA, and one study included patients with lumbar OA. Trial durations varied between 1 and 12 weeks. Of the three studies on topical ibuprofen, two were of 1-week duration and one lasted 2 weeks. Trial durations were 12 weeks for three of the four studies on topical ketoprofen. Few trials were specifically designed to compare oral and topical NSAIDs with placebo [35, 44, 46]. Most of the manuscripts retrieved did not adequately report $\mathrm{AE}$ data such that these could be used for a meta-analysis, or they did not provide all treatment-emergent $\mathrm{AE}$ data for all the randomized patients. The risk of selective outcome reporting bias was therefore judged as 'high' for more than $50 \%$ of the included studies. Figures 2 and 3 include a summary of the risk of bias assessed for each study included in the qualitative synthesis, as well as the risk of bias items presented as percentages across all these studies, except the two studies whose results were only published as post hoc and pooled analyses. In fact, we could not assess the risk of bias in the two studies for which we received only the raw data from their sponsor because we did not receive information on most of the risk of bias domains (neither were these published). In total, full safety data were provided by the authors of the manuscripts or the sponsors of the studies for 12 of the 19 trials included in the meta-analysis, substantially limiting the impact of the selective reporting bias on the results of this meta-analysis.

\subsection{Results for all Topical Non-steroidal Anti-inflammatory Drugs (NSAIDs)}

\subsubsection{Primary Outcomes}

The main SOCs that are more likely to be affected by the use of topical NSAIDs, as well as those that have been shown to be 
Fig. 1 Study selection process

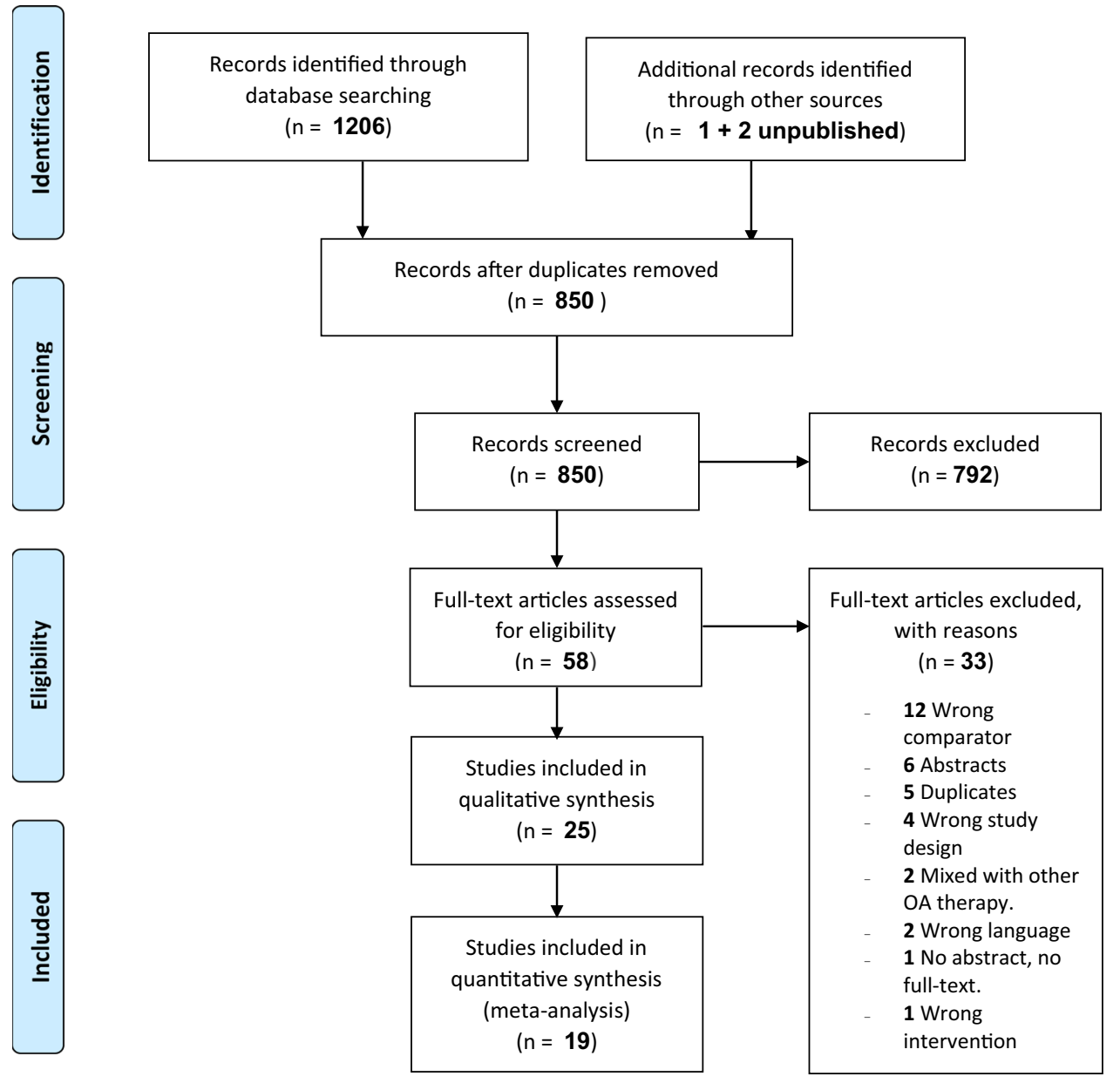

harmed by the use of oral NSAIDs, were considered as primary outcomes in this meta-analysis. Overall, we found no statistically significant increase in odds of AEs for topical NSAIDs versus placebo, for any of the SOCs considered. In particular, there was no statistically significant increase in odds, neither for GI disorders (OR 0.96, 95\% CI 0.73-1.27; $I^{2}=0.0 \%$ ) (Fig. 4) nor for vascular (OR 1.21, 95\% CI 0.72-2.03) or cardiac disorders (OR 2.26, 95\% CI 0.86-5.94). Although the odds for cardiac disorders appear to be higher in patients receiving topical NSAIDs than in those receiving placebo, the number of events in each group does not justify any concern.

Serious and severe AEs were also assessed as co-primary outcomes in this meta-analysis. Overall, there were no more serious (OR $0.79,95 \%$ CI $0.37-1.71 ; I^{2}=0 \%$ ) or severe (OR $1.19,95 \%$ CI $0.72-1.97 ; I^{2}=10.9 \%$ ) AEs in patients receiving topical NSAIDs than in those receiving placebo. Detailed results for all primary outcomes are provided in ESM 2.

\subsubsection{Secondary Outcomes}

Dropouts due to AEs, and the number of patients who experienced any $\mathrm{AE}$ at least once during the trials, were defined as secondary outcomes in this meta-analysis. Overall, there was a $16 \%$ increase in odds for total AEs with topical NSAIDs versus placebo, which was statistically significant (OR 1.16, 95\% CI $1.04-1.29 ; I^{2}=0 \%$ ). Dropouts due to AEs were significantly more frequent in patients receiving topical NSAIDs than in those receiving placebo; the use of topical NSAIDs was associated with a near $50 \%$ increase in odds of withdrawals due to AEs compared with placebo (OR 1.49, 95\% CI 1.15-1.92; $\left.I^{2}=0 \%\right)(\mathrm{ESM} 2)$.

\subsection{Results for Individual Topical NSAIDs}

\subsubsection{Diclofenac}

Eight studies involving topical diclofenac versus placebo were included in the analysis. Overall, there was a significant increase in AEs (total AEs) with topical diclofenac compared with placebo (OR 1.30, 95\% CI 1.10-1.53; $I^{2}=0 \%$ ). The rate of withdrawals due to AEs was significantly twice as high with topical diclofenac compared with placebo (OR $2.00,95 \%$ CI $\left.1.27-3.14 ; I^{2}=0 \%\right)$. The higher rate of total AEs in patients receiving topical diclofenac seems to be 


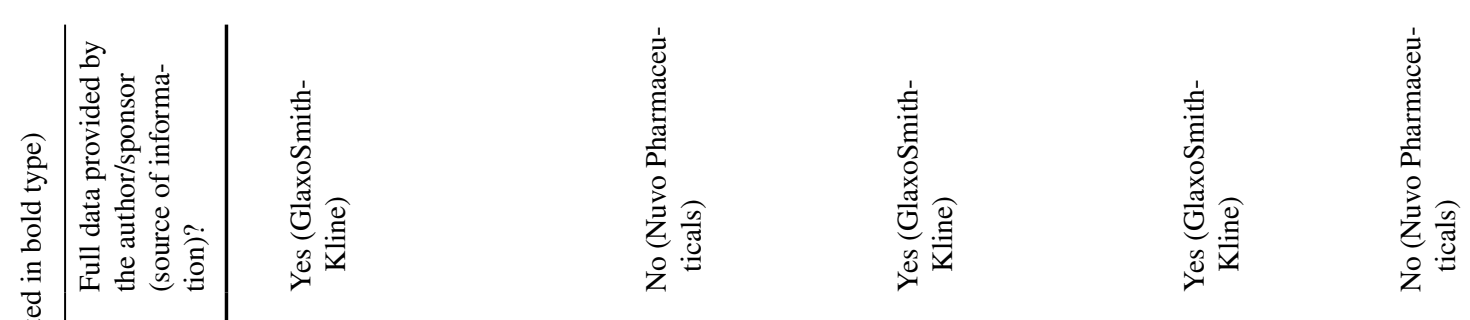

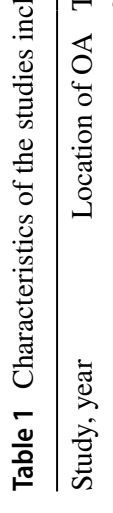

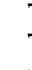

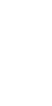

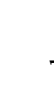$$
\text { (1) }
$$

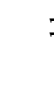$$
\text { 西 }
$$

西

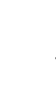

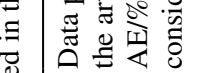

:

递

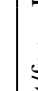

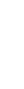

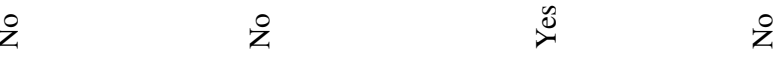

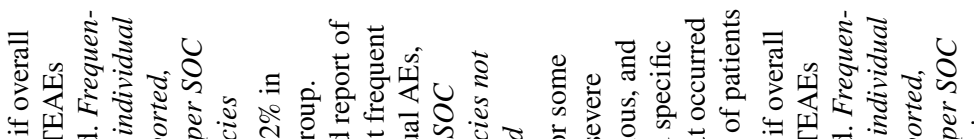

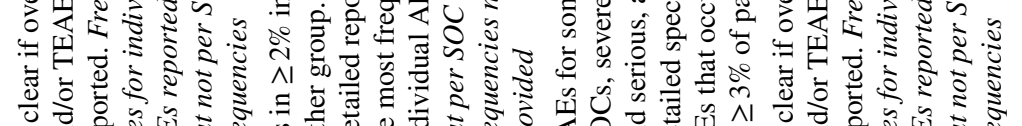

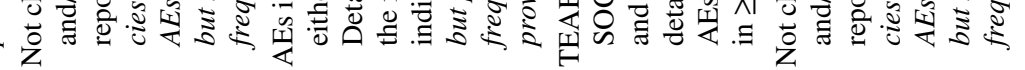

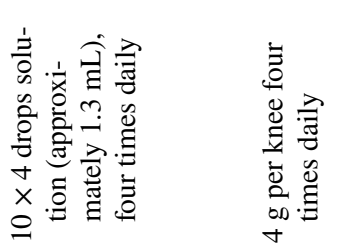

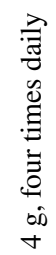

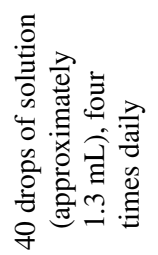

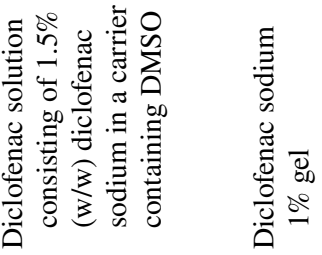
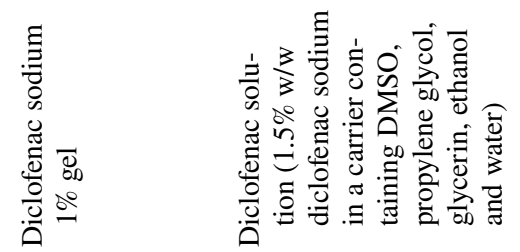

竞

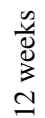

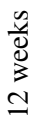

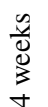

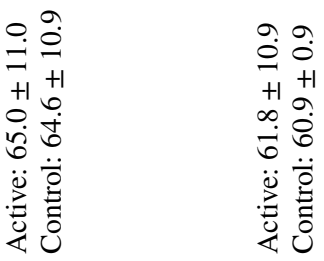

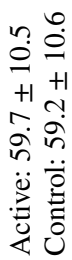

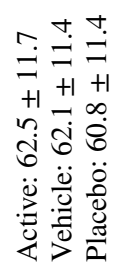

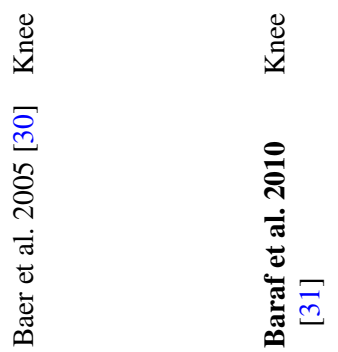

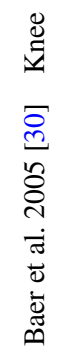
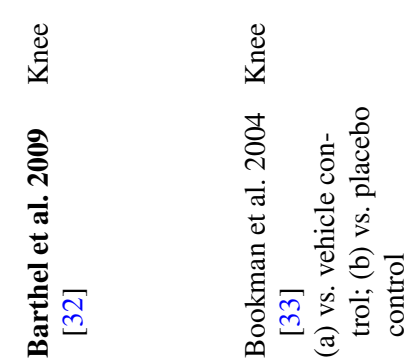


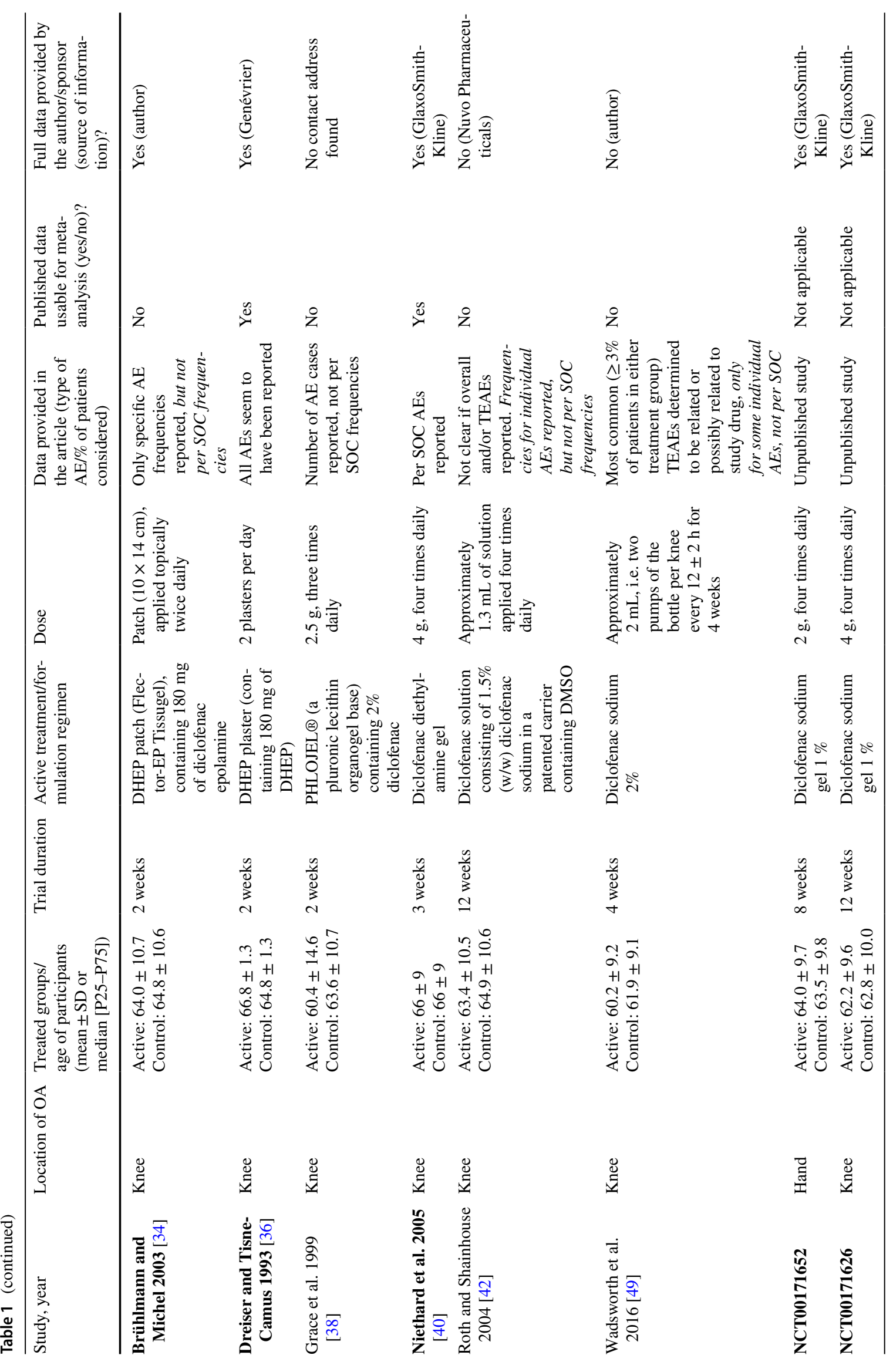




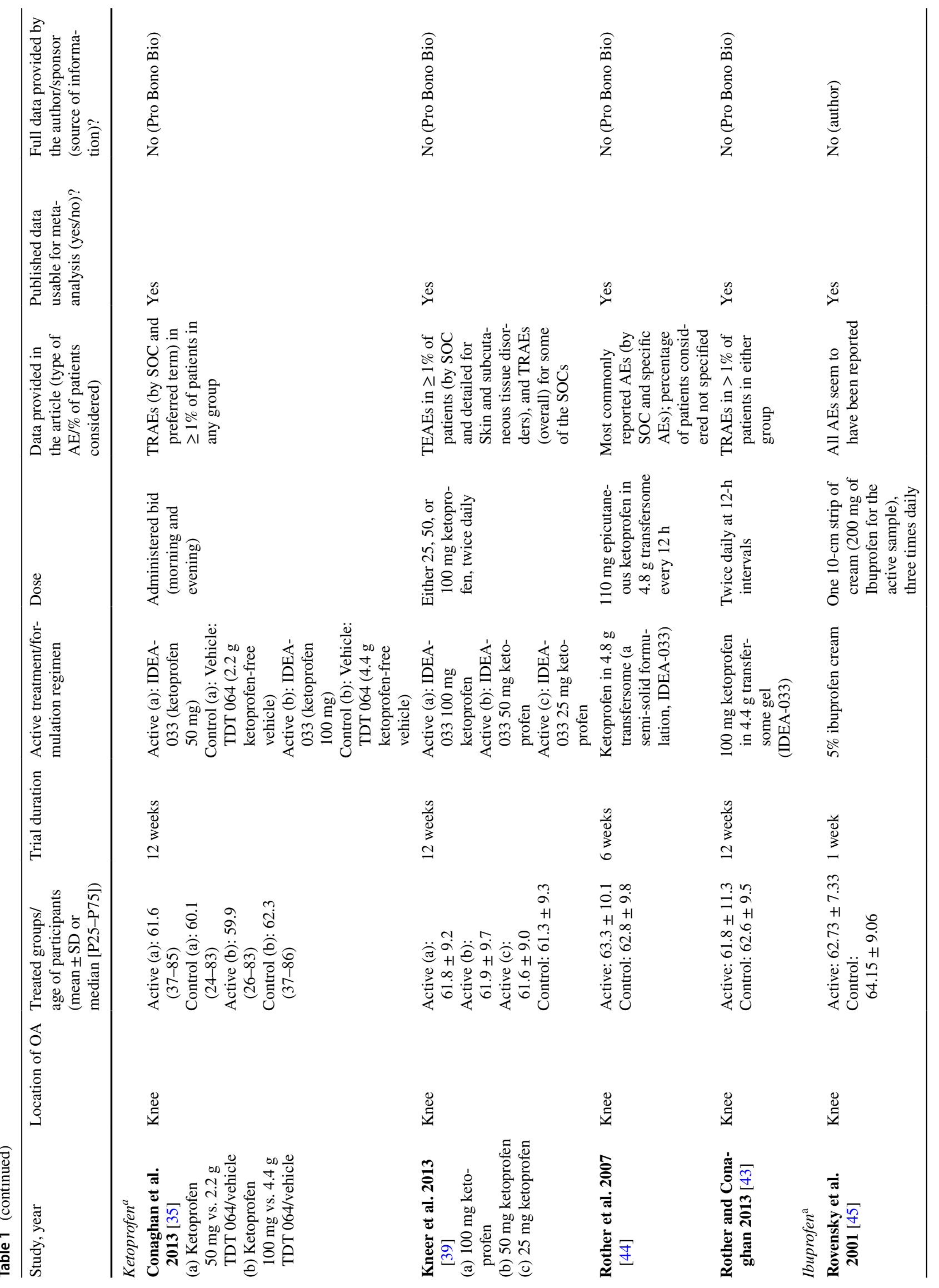




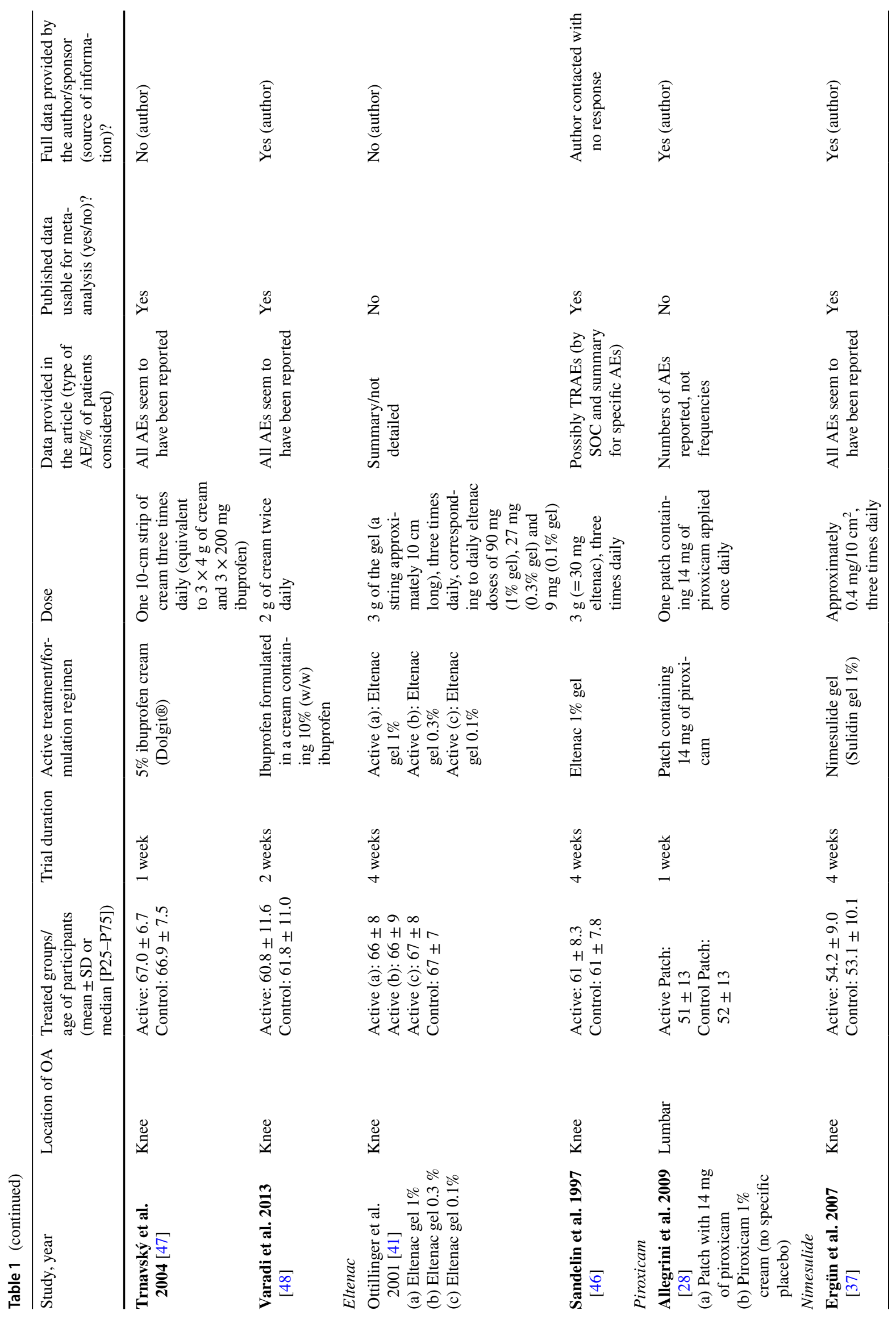




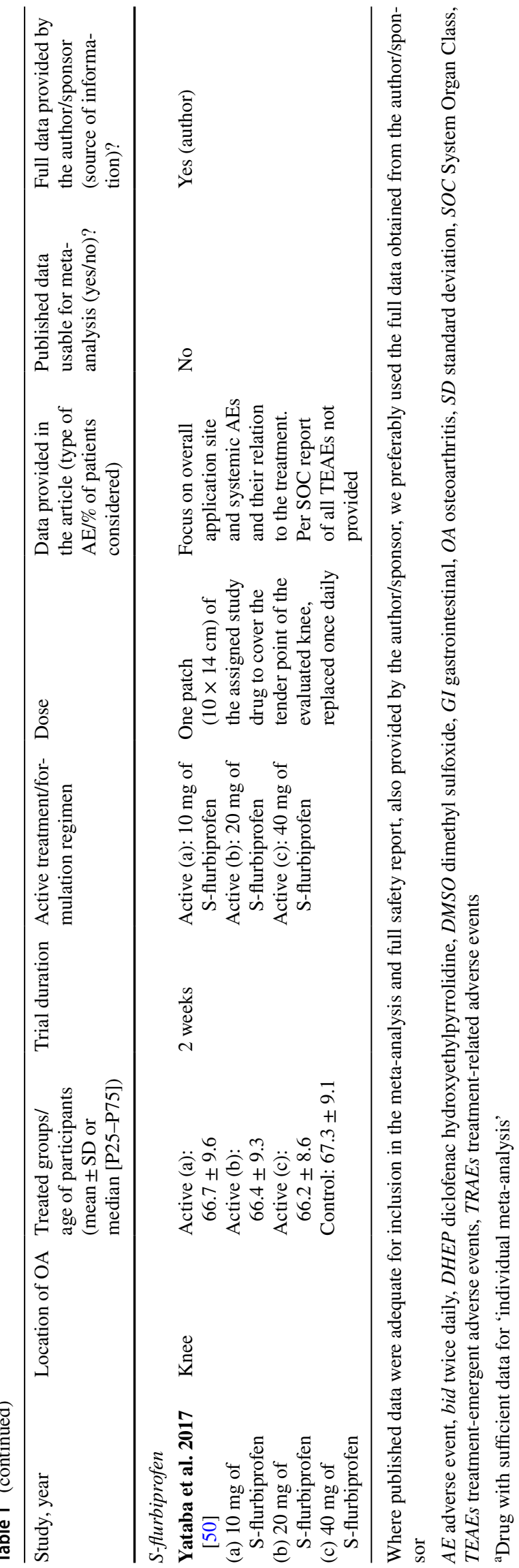

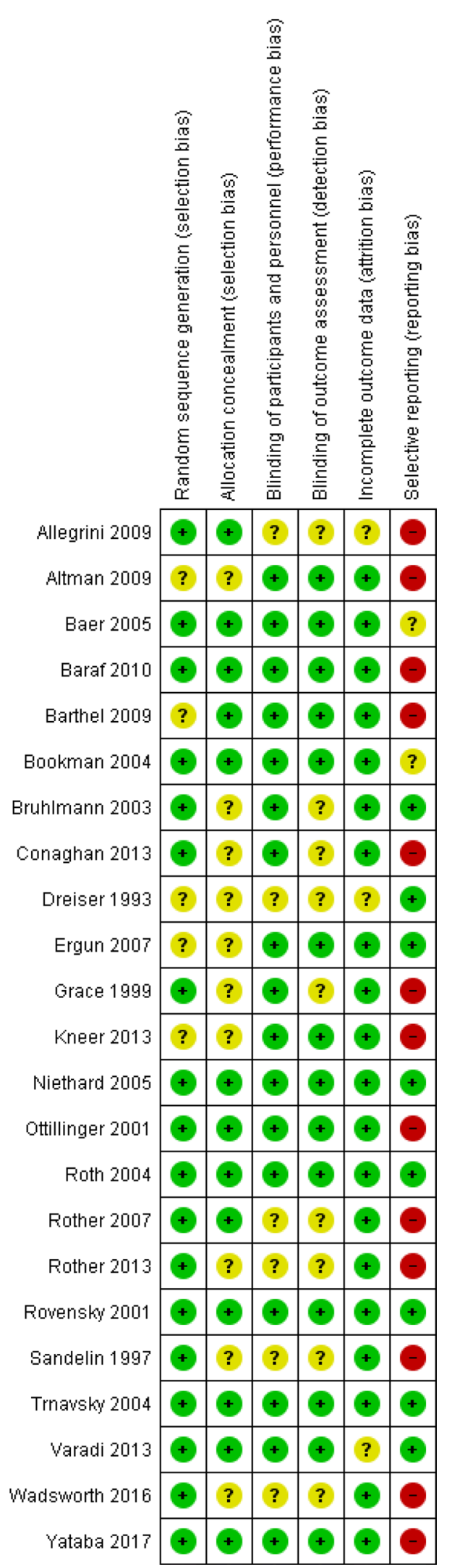

Fig. 2 Risk of bias summary: review authors' judgements about each risk of bias item for each study included in the qualitative synthesis. Note: This figure does not include the two diclofenac NCT studies, as explained in Sect. 3 
Fig. 3 Risk of bias graph: review authors' judgements about each risk of bias item presented as percentages across all studies included in the qualitative synthesis. Note: This figure does not include information on risk of bias for the two diclofenac NCT studies, as explained in Sect. 3; thus, the summaries made here are based on data from 23 studies

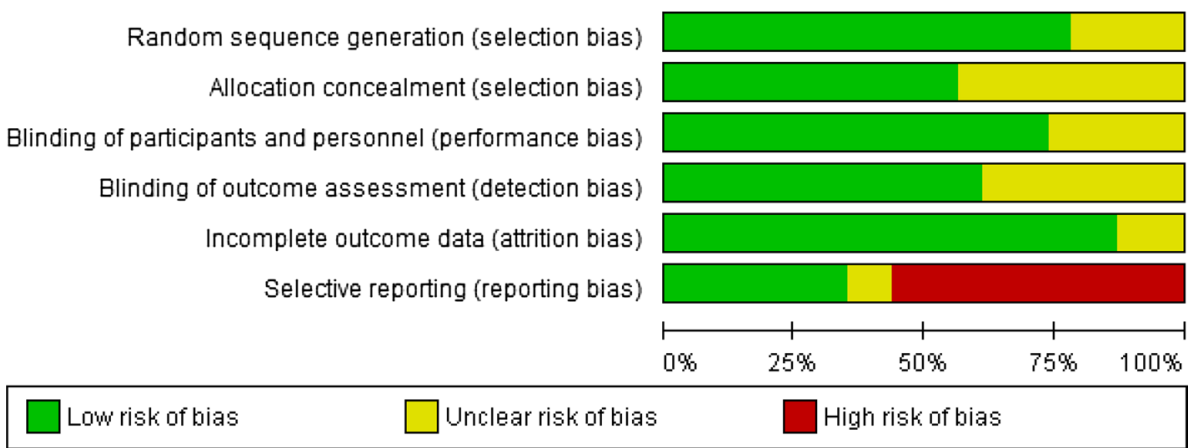

Topical NSAIDs: Gastrointestinal disorders

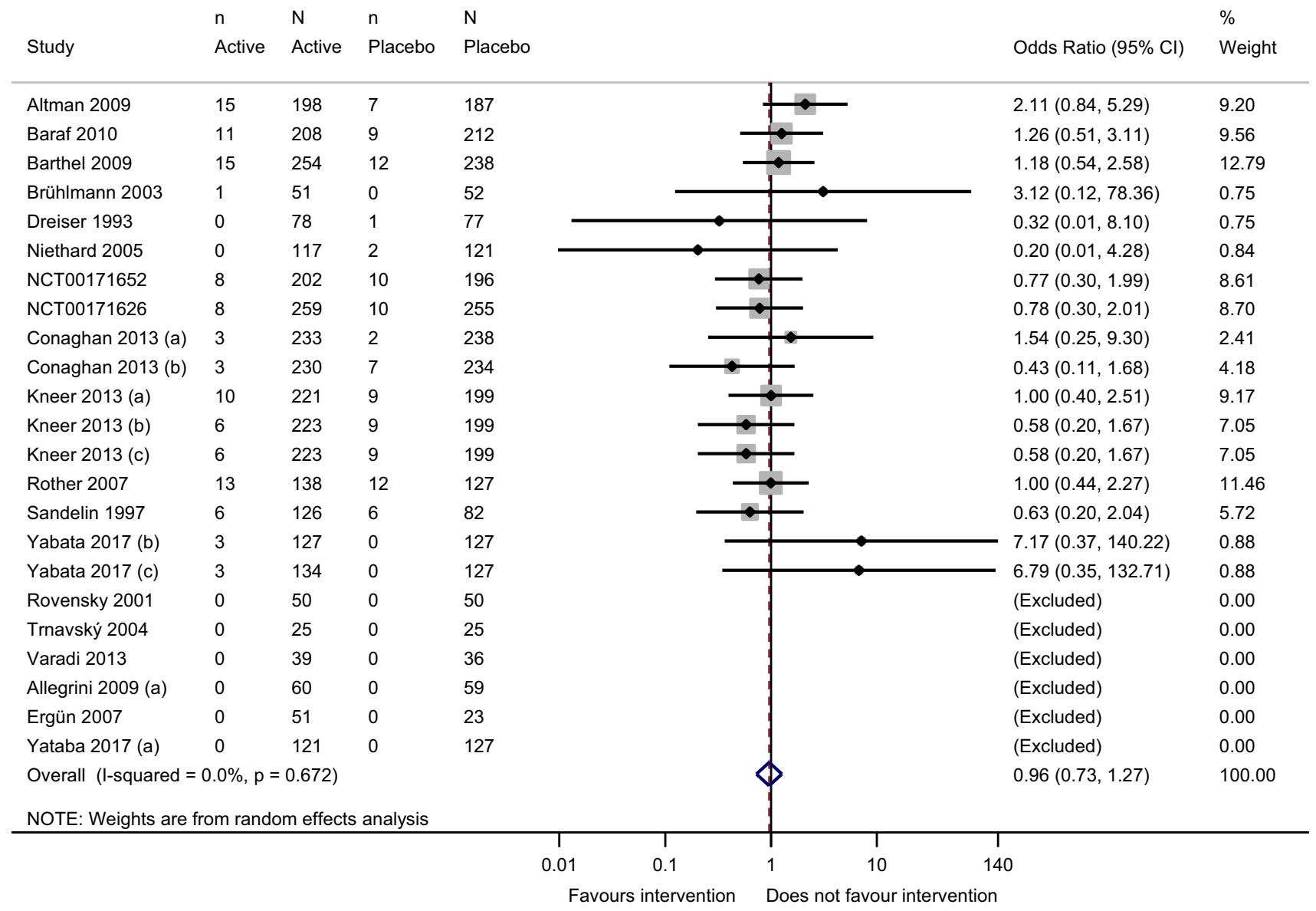

Fig. 4 Forest plot displaying the results of the meta-analysis comparing gastrointestinal disorders for all topical NSAIDs versus placebo in patients with osteoarthritis. NSAIDs non-steroidal anti-inflammatory drugs, $C I$ confidence interval

driven by the higher odds for skin and subcutaneous tissue disorders with topical diclofenac compared with placebo, although the difference was not statistically significant (OR 1.73, 95\% CI 0.96-3.10) (ESM 2).

There was no statistically significant difference in odds for severe (OR 1.19, 95\% CI 0.68-2.07; $I^{2}=23.9 \%$ ) or serious AEs (OR $0.94,95 \%$ CI $0.26-3.42 ; I^{2}=0 \%$ ), or for specific SOC-related AEs, in patients who were treated with diclofenac compared with those who were receiving placebo. In particular, topical diclofenac was associated with no GI toxicity (OR 1.11, 95\% CI 0.75-1.64; $I^{2}=0 \%$ ) (Fig. 5).

\subsubsection{Ketoprofen}

Four studies involving topical ketoprofen versus placebo were included in the analysis. Overall, there was no 
Diclofenac: Gastrointestinal disorders

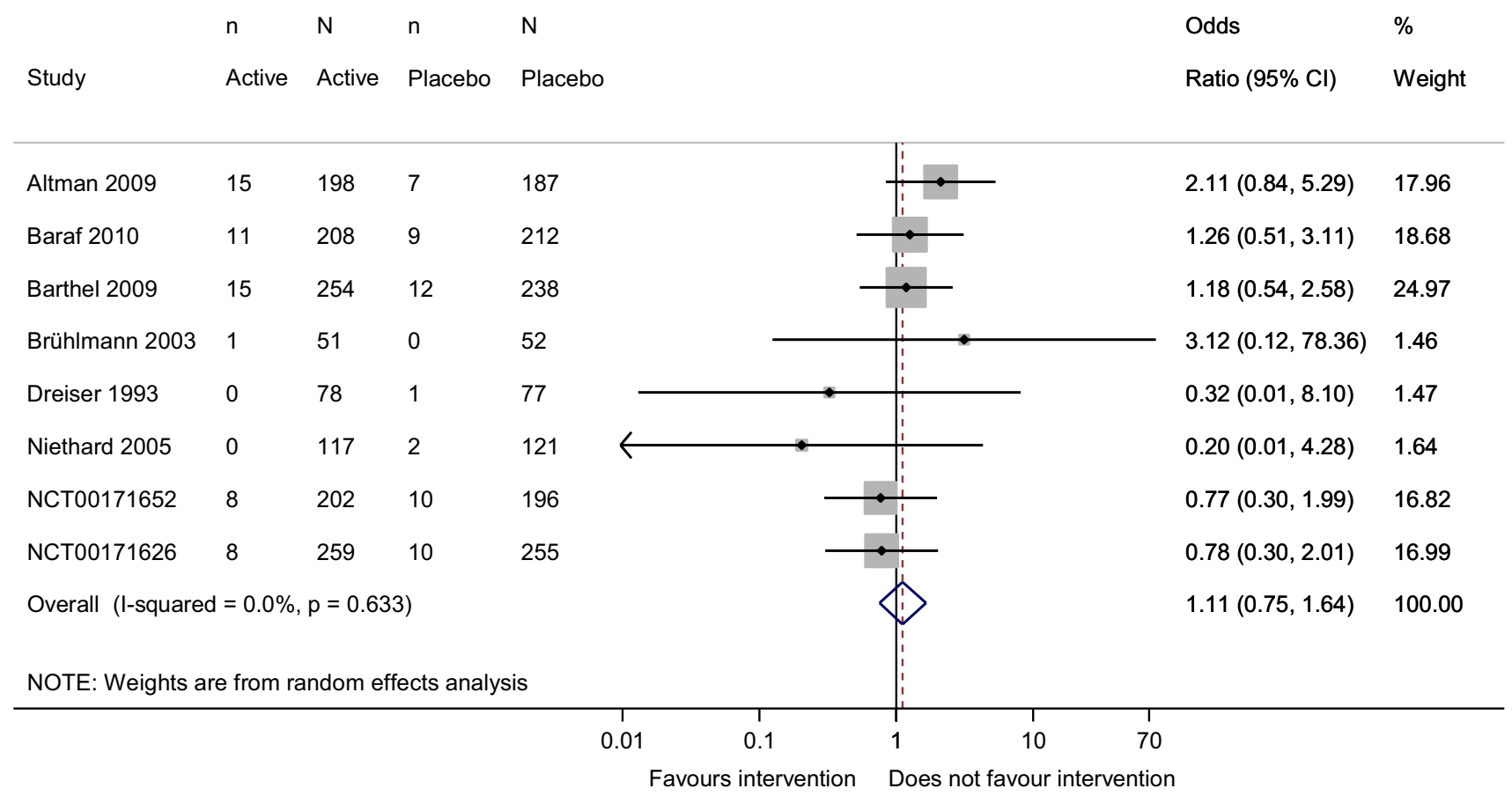

Fig. 5 Forest plot displaying the results of the meta-analysis comparing gastrointestinal disorders with topical diclofenac versus placebo in patients with osteoarthritis, $C I$ confidence interval

difference in the rate of total AEs observed between topical ketoprofen and placebo (OR 1.04, 95\% CI 0.90-1.20; $I^{2}=0 \%$ ). A tendency for slightly more withdrawals due to AEs was observed with topical ketoprofen compared with placebo, but the OR did not reach statistical significance (OR 1.37, 95\% CI 0.99-1.89; $I^{2}=0 \%$ ) (ESM 2).

We found significantly fewer nervous system disorders reported with topical ketoprofen compared with placebo, with headache being the most frequently reported specific event in the placebo group (OR 0.60, 95\% CI 0.41-0.88; $\left.I^{2}=0 \%\right)$. Neither was there any statistically significant effect for events, including skin and subcutaneous tissue disorders, GI disorders (OR $0.78,95 \%$ CI $0.51-1.21 ; I^{2}=0 \%$ ), cardiac or vascular disorders, musculoskeletal and connective tissue disorders, serious AEs, or severe AEs.

\subsubsection{Ibuprofen}

Three studies involving topical ibuprofen versus placebo were included in the analysis. No statistically significant effect was observed for a difference in the rate of AEs in all SOCs between ibuprofen and placebo, or for serious and severe AEs (ESM 2).

\subsection{Assessment of Publication Bias}

We assessed funnel plot asymmetry for publication bias, for each of the outcomes; only all 'topical NSAIDs' had sufficient studies for the Harbord test for funnel plot asymmetry. Only three studies on topical ibuprofen were available for the meta-analysis, with several null events; thus, there were insufficient data to perform the analyses for publication bias. Visual inspection of funnel plots and a formal test for funnel plot asymmetry (Harbord test) showed that there was no publication bias, whatever the outcome or treatment (Fig. 6 and ESM 3).

\subsection{GRADE Assessment of Findings}

Using the GRADE approach [24], we assessed the certainty of evidence for each of the outcomes, for all topical NSAIDs and for individual topical NSAIDs, and, overall, found a 'high' certainty of evidence with most of the outcomes assessed. The high risk of outcome reporting bias found with topical ketoprofen downgraded the evidence to 'moderate' for most of the outcomes. The results for the main outcomes for all topical NSAIDs, topical diclofenac, and topical ketoprofen are depicted in the summary of findings tables (Tables 2, 3 and 4). 
Fig. 6 Assessment of publication bias: funnel plots for total adverse events with a all topical NSAIDs, b topical diclofenac, and $\mathbf{c}$ topical ketoprofen. (These funnel plots are based on the data used for the meta-analyses of 'any AEs' for each single NSAID or for all topical NSAIDs; these analyses were those including as much data as possible). NSAIDs non-steroidal anti-inflammatory drugs, $A E s$ adverse events, $O R$ odds ratio

\section{A All topical NSAIDs}

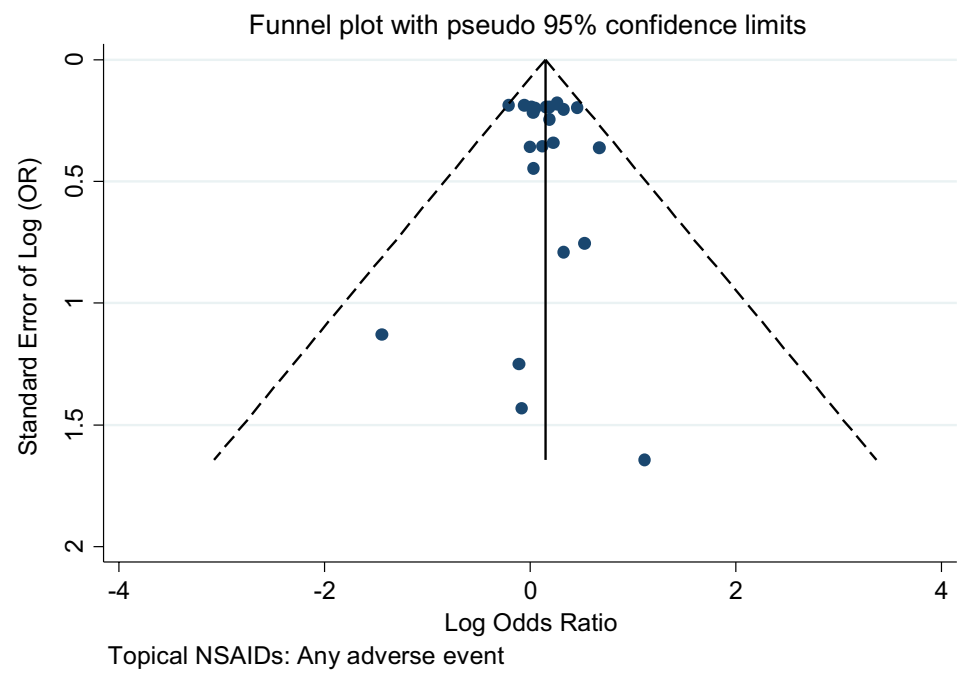

Harbord's modified test: $p=0.91$

\section{B Topical diclofenac}

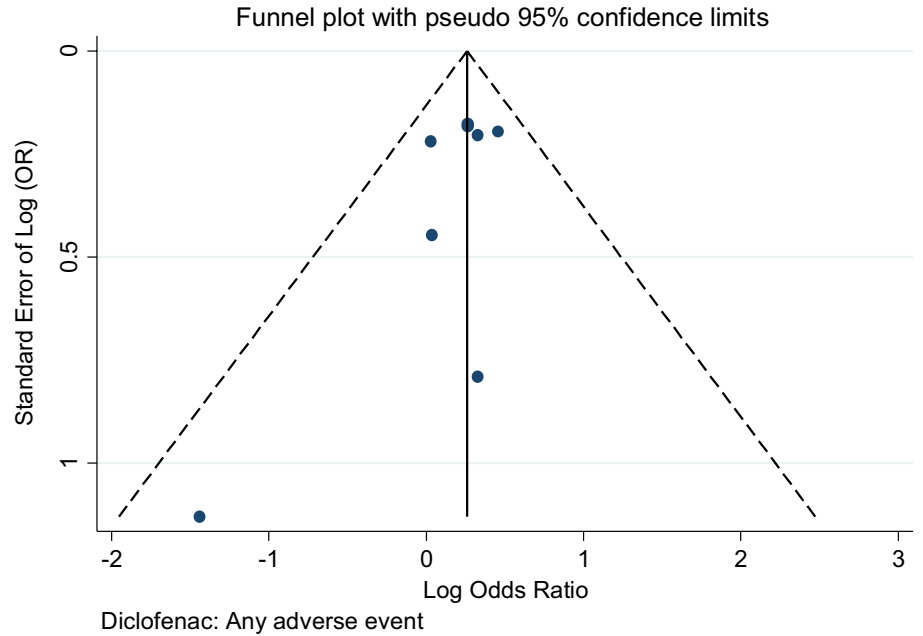

\section{Topical ketoprofen}

Funnel plot with pseudo 95\% confidence limits

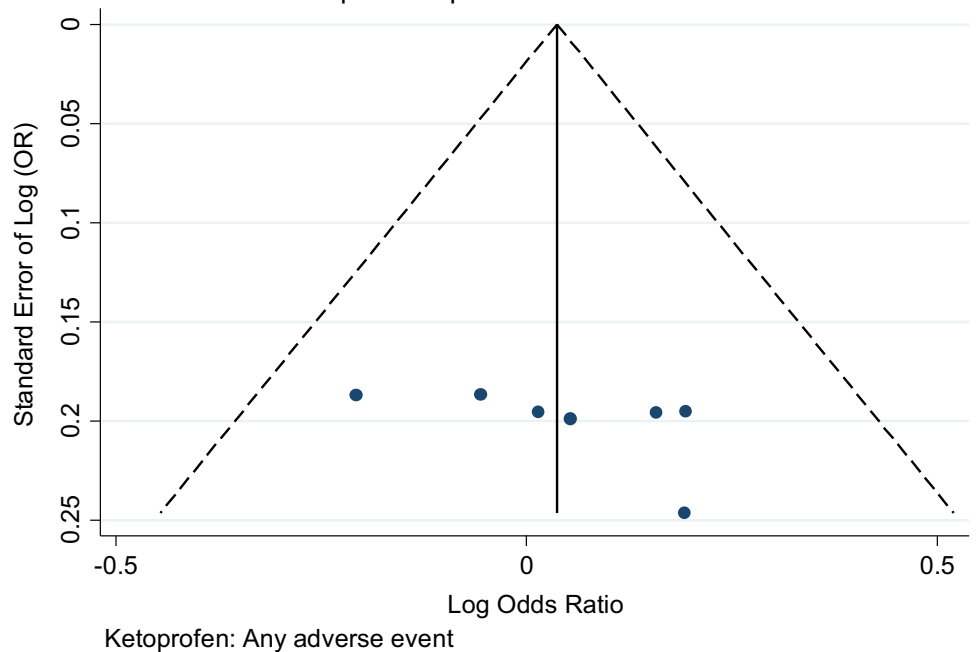

Ketoprofen: Any adverse event 
Table 2 Summary of findings for topical NSAIDs compared with placebo in patients with osteoarthritis

\begin{tabular}{|c|c|c|c|c|c|}
\hline \multirow[t]{2}{*}{ Outcomes } & \multirow{2}{*}{$\begin{array}{l}\text { No. of participants } \\
\text { (studies) }\end{array}$} & \multirow{2}{*}{$\begin{array}{l}\text { Certainty of } \\
\text { the evidence } \\
\text { (GRADE) }\end{array}$} & \multirow[t]{2}{*}{ Relative effect (95\% CI) } & \multicolumn{2}{|c|}{ Anticipated absolute effects } \\
\hline & & & & Risk with placebo & $\begin{array}{l}\text { Risk difference with topi- } \\
\text { cal NSAIDs }\end{array}$ \\
\hline $\begin{array}{l}\text { Skin and subcutaneous } \\
\text { tissue disorders }\end{array}$ & 6461 (19 RCTs) & $\begin{array}{l}\bigoplus \bigoplus \bigoplus \bigoplus \\
\text { HIGH }\end{array}$ & OR $1.12(0.93-1.34)$ & 62 per 1000 & $\begin{array}{l}7 \text { more per } 1000 \text { ( } 4 \text { fewer } \\
\text { to } 19 \text { more) }\end{array}$ \\
\hline $\begin{array}{l}\text { Gastrointestinal disor- } \\
\text { ders }\end{array}$ & 5906 (18 RCTs) & $\begin{array}{l}\bigoplus \bigoplus \bigoplus \bigoplus \\
\text { HIGH }\end{array}$ & OR $0.96(0.73-1.27)$ & 34 per 1000 & $\begin{array}{l}1 \text { fewer per } 1000 \text { ( } 9 \text { fewer } \\
\text { to } 9 \text { more) }\end{array}$ \\
\hline Cardiac disorders & 6253 (18 RCTs) & $\begin{array}{l}\bigoplus \bigoplus \bigoplus \bigcirc \\
\text { MODERATE }^{\mathrm{a}}\end{array}$ & OR $2.26(0.86-5.94)$ & 1 per 1000 & $\begin{array}{l}2 \text { more per } 1000 \text { ( } 0 \text { fewer } \\
\text { to } 7 \text { more) }\end{array}$ \\
\hline Vascular disorders & 6253 (18 RCTs) & $\begin{array}{l}\bigoplus \bigoplus \bigoplus \bigoplus \\
\text { HIGH }\end{array}$ & OR $1.21(0.72-2.03)$ & 8 per 1000 & $\begin{array}{l}2 \text { more per } 1000 \text { ( } 2 \text { fewer } \\
\text { to } 8 \text { more) }\end{array}$ \\
\hline $\begin{array}{l}\text { Nervous system dis- } \\
\text { orders }\end{array}$ & 6461 (19 RCTs) & $\begin{array}{l}\bigoplus \bigoplus \bigoplus \bigoplus \\
\text { HIGH }\end{array}$ & OR $0.91(0.75-1.11)$ & 69 per 1000 & $\begin{array}{l}6 \text { fewer per } 1000 \text { ( } 16 \\
\text { fewer to } 7 \text { more) }\end{array}$ \\
\hline Serious adverse events & 5035 (16 RCTs) & $\begin{array}{l}\bigoplus \bigoplus \bigoplus \bigoplus \\
\text { HIGH }\end{array}$ & OR $0.79(0.37-1.71)$ & 8 per 1000 & $\begin{array}{l}2 \text { fewer per } 1000 \text { ( } 5 \text { fewer } \\
\text { to } 5 \text { more) }\end{array}$ \\
\hline
\end{tabular}

The risk in the intervention group (and its $95 \% \mathrm{CI}$ ) is based on the assumed risk in the comparison group and the relative effect of the intervention (and its $95 \% \mathrm{CI}$ )

GRADE Working Group grades of evidence: High certainty we are very confident that the true effect lies close to that of the estimate of the effect; Moderate certainty we are moderately confident in the effect estimate: the true effect is likely to be close to the estimate of the effect, but there is a possibility that it is substantially different; Low certainty our confidence in the effect estimate is limited: the true effect may be substantially different from the estimate of the effect; Very low certainty we have very little confidence in the effect estimate: the true effect is likely to be substantially different from the estimate of effect

$C I$ confidence interval, GRADE Grading of Recommendations Assessment, Development and Evaluation, NSAIDs non-steroidal anti-inflammatory drugs, $O R$ odds ratio, $R C T$ s randomized controlled trials

${ }^{a}$ Wide CI because of the few numbers of events

\section{Discussion}

Overall, this meta-analysis found a small but statistically significant increase in odds of total AEs $(+16 \%)$ for all topical NSAIDs compared with placebo, and a $49 \%$ increase in dropouts due to AEs, but no statistically significant effect in the individual SOCs investigated. In fact, where there were differences in odds between topical NSAIDs (overall or individual NSAIDs) and placebo for individual SOC analysis, these differences did not reach statistical significance. The frequency of serious AEs was lower with topical NSAIDs (overall) compared with placebo $(-21 \%)$, although severe AEs were reported more often $(+19 \%)$; however, neither of these results was statistically significant. This evidence was associated with 'high' certainties, apart from the 'cardiac disorders' outcome, which was associated with a 'moderate' certainty of evidence due to a large imprecision around the combined effect size.

As reported hereunder, our study found a near $50 \%$ increased odds of withdrawal due to AEs with topical NSAIDs versus placebo (OR 1.49, 95\% CI 1.15-1.92). This is in agreement with the results of a recent fixed-effect metaanalysis on the safety of topical NSAIDs versus placebo (in RCTs) (OR 1.56, 95\% CI 1.21-2.00) [13]. The differences in the dropout rates between topical NSAIDs and placebo might be largely due to the high, but not statistically significant, odds for skin and subcutaneous tissue disorders in the treated group compared with placebo, mainly driven by topical diclofenac. However, the AEs that led participants to withdraw might be minor events as we found no statistically significant effect in terms of overall severe or serious AEs.

For SOC comparisons, moderate differences in the OR for AEs were found between all topical NSAIDs and placebo (skin $+12 \%$, GI disorders $-4 \%$, nervous system $-9 \%$, vascular disorders $+21 \%$ ), with the exception of cardiac disorders, which were increased more than twofold with topical NSAIDs versus placebo (OR 2.26, 95\% CI 0.86-5.94), although the difference was not statistically significant. However, it is important to note that there should not be any major concerns in this regard because of the very high number of studies with null events (for cardiac disorders), both in the intervention and control groups, which explains the large imprecision around the overall effect estimate. In our study, the GI toxicity reported with topical NSAIDs was similar to that of placebo, and confirms earlier reports of a reduced risk of upper GI AEs with topical NSAIDs compared with oral NSAIDs [8, 10, 51].

A higher rate of skin reactions with topical NSAIDs has been reported in the literature, ranging from 10 to $39 \%$ [9, 
Table 3 Summary of findings for topical diclofenac compared with placebo in patients with osteoarthritis

\begin{tabular}{|c|c|c|c|c|c|}
\hline \multirow[t]{2}{*}{ Outcomes } & \multirow{2}{*}{$\begin{array}{l}\text { No. of partici- } \\
\text { pants (studies) }\end{array}$} & \multirow{2}{*}{$\begin{array}{l}\text { Certainty of } \\
\text { the evidence } \\
\text { (GRADE) }\end{array}$} & \multirow[t]{2}{*}{ Relative effect (95\% CI) } & \multicolumn{2}{|c|}{ Anticipated absolute effects } \\
\hline & & & & Risk with placebo & $\begin{array}{l}\text { Risk difference with topical } \\
\text { diclofenac }\end{array}$ \\
\hline $\begin{array}{l}\text { Skin and subcutaneous } \\
\text { tissue disorders }\end{array}$ & 2705 (8 RCTs) & $\begin{array}{l}\bigoplus \bigoplus \bigoplus \bigoplus \bigoplus \\
\mathrm{HIGH}\end{array}$ & OR $1.73(0.96-3.10)$ & 21 per 1000 & $\begin{array}{l}15 \text { more per } 1000 \text { ( } 1 \text { fewer to } 41 \\
\text { more) }\end{array}$ \\
\hline Gastrointestinal disorders & 2705 (8 RCTs) & $\begin{array}{l}\bigoplus \bigoplus \bigoplus \bigoplus \\
\text { HIGH }\end{array}$ & OR $1.11(0.75-1.64)$ & 38 per 1000 & $\begin{array}{l}4 \text { more per } 1000 \text { ( } 9 \text { fewer to } 23 \\
\text { more) }\end{array}$ \\
\hline Cardiac disorders & 2705 (8 RCTs) & $\begin{array}{l}\bigoplus \bigoplus \bigoplus \bigcirc \\
\text { MODERATE }\end{array}$ & OR $1.59(0.26-9.73)$ & 2 per 1000 & $\begin{array}{l}1 \text { more per } 1000 \text { ( } 2 \text { fewer to } 19 \\
\text { more) }\end{array}$ \\
\hline Vascular disorders & 2705 (8 RCTs) & $\begin{array}{l}\bigoplus \bigoplus \bigoplus \bigoplus \bigoplus \\
\text { HIGH }\end{array}$ & OR $1.19(0.53-2.66)$ & 11 per 1000 & $\begin{array}{l}2 \text { more per } 1000 \text { ( } 5 \text { fewer to } 18 \\
\text { more) }\end{array}$ \\
\hline Nervous system disorders & 2705 (8 RCTs) & $\begin{array}{l}\bigoplus \bigoplus \bigoplus \bigoplus \bigoplus \\
\text { HIGH }\end{array}$ & OR $1.01(0.80-1.28)$ & 122 per 1000 & $\begin{array}{l}1 \text { more per } 1000 \text { ( } 22 \text { fewer to } 29 \\
\text { more) }\end{array}$ \\
\hline Serious adverse events & 1279 (5 RCTs) & $\begin{array}{l}\bigoplus \bigoplus \bigoplus \bigoplus \\
\text { HIGH }\end{array}$ & OR $0.94(0.26-3.42)$ & 8 per 1000 & $\begin{array}{l}0 \text { fewer per } 1000 \text { ( } 6 \text { fewer to } 19 \\
\text { more) }\end{array}$ \\
\hline
\end{tabular}

The risk in the intervention group (and its $95 \% \mathrm{CI}$ ) is based on the assumed risk in the comparison group and the relative effect of the intervention (and its 95\% CI)

GRADE Working Group grades of evidence: High certainty we are very confident that the true effect lies close to that of the estimate of the effect; Moderate certainty we are moderately confident in the effect estimate: the true effect is likely to be close to the estimate of the effect, but there is a possibility that it is substantially different; Low certainty our confidence in the effect estimate is limited: the true effect may be substantially different from the estimate of the effect; Very low certainty we have very little confidence in the effect estimate: the true effect is likely to be substantially different from the estimate of effect

$C I$ confidence interval, GRADE Grading of Recommendations Assessment, Development and Evaluation, $O R$ odds ratio, $R C T s$ randomized controlled trials

${ }^{a}$ Wide CI because of the few numbers of events

52], which was not borne out by our analysis for all topical NSAIDs (OR 1.12, 95\% CI 0.93-1.34). The increase in skin reactions may be product-specific. In fact, our results for topical diclofenac showed an increase in odds for skin and subcutaneous tissue disorders, although this was not statistically significant (OR 1.73, 95\% CI 0.96-3.10); for topical ketoprofen and topical ibuprofen, such an increase was not observed. This is consistent with the Cochrane review of topical NSAIDs that found an increase in local skin AEs with topical diclofenac, but no increase with topical ketoprofen [10]. Although the difference in our study is not statistically significant (particularly regarding topical diclofenac), our estimation is more precise than previous analyses as we collected full safety data for most of the studies included in the analysis. A meta-analysis of nine RCTs on topical diclofenac found a higher incidence of AEs, including dry skin, rash, dermatitis and neck pain, and a higher incidence of withdrawals versus placebo [53].

As previously stated, we found no increased odds of skin and subcutaneous tissue disorders with topical ketoprofen, in placebo-controlled trials, as reported by Derry et al. [10]. On the contrary, a recent systematic review of five RCTs did find that the most commonly reported $\mathrm{AE}$ associated with the use of topical ketoprofen in transfersome gel was non-severe skin and subcutaneous tissue disorders (erythema) [54]; however, one of those five studies was an open-label study. Additionally, as this was not a meta-analysis, its results should be taken with caution, compared with those found from meta-analyses.

For individual topical NSAIDs, from the three studies included with ibuprofen, no statistically significant difference in the rate of AEs was observed compared with placebo. However, there is a need for further RCTs regarding topical ibuprofen in order to better estimate its safety profile.

With ketoprofen, data from four placebo-controlled RCTs showed no statistically significant difference in the rate of AEs, for total AEs (OR 1.04, 95\% CI 0.90-1.20) and for all SOC-related AEs, with the exception of nervous system disorders. In fact, the data showed a reduced odds of nervous system disorders $(-40 \%)$, mainly headache, with ketoprofen compared with placebo (OR 0.60, 95\% CI 0.41-0.88).

From the eight studies of diclofenac versus placebo included in the analysis, diclofenac was associated with a significant increase in odds of total AEs $(+30 \%)$, and twice as many withdrawals due to AEs compared with placebo (OR 2.00, 95\% CI 1.27-3.14). The number of AEs associated with diclofenac was largely driven by the increase in skin and subcutaneous tissue disorders $(+73 \%)$, although 
Table 4 Summary of findings for topical ketoprofen compared with placebo in patients with osteoarthritis

\begin{tabular}{|c|c|c|c|c|c|}
\hline \multirow[t]{2}{*}{ Outcomes } & \multirow{2}{*}{$\begin{array}{l}\text { No. of partici- } \\
\text { pants (studies) }\end{array}$} & \multirow{2}{*}{$\begin{array}{l}\text { Certainty of } \\
\text { the evidence } \\
\text { (GRADE) }\end{array}$} & \multirow[t]{2}{*}{ Relative effect (95\% CI) } & \multicolumn{2}{|c|}{ Anticipated absolute effects } \\
\hline & & & & Risk with placebo & $\begin{array}{l}\text { Risk difference with topical } \\
\text { ketoprofen }\end{array}$ \\
\hline $\begin{array}{l}\text { Skin and subcutaneous } \\
\text { tissue disorders }\end{array}$ & 2621 (4 RCTs) & $\begin{array}{l}\bigoplus \bigoplus \bigoplus \bigcirc \\
\text { MODERATE }^{\mathrm{a}}\end{array}$ & OR $1.02(0.83-1.25)$ & 129 per 1000 & $\begin{array}{l}2 \text { more per } 1000 \text { ( } 20 \text { fewer to } 27 \\
\text { more) }\end{array}$ \\
\hline Gastrointestinal disorders & 2066 (3 RCTs) & $\begin{array}{l}\bigoplus \bigoplus \bigoplus \bigcirc \\
\text { MODERATE }^{\mathrm{a}}\end{array}$ & OR $0.78(0.51-1.21)$ & 38 per 1000 & $\begin{array}{l}8 \text { fewer per } 1000 \text { ( } 18 \text { fewer to } 8 \\
\text { more) }\end{array}$ \\
\hline Cardiac disorders & 2621 (4 RCTs) & $\begin{array}{l}\bigoplus \bigoplus \bigcirc \bigcirc \\
\text { LOW }^{\mathrm{a}}\end{array}$ & OR $2.65(0.70-10.07)$ & 1 per 1000 & $\begin{array}{l}2 \text { more per } 1000 \text { ( } 0 \text { fewer to } 8 \\
\text { more) }\end{array}$ \\
\hline Vascular disorders & 2621 (4 RCTs) & $\begin{array}{l}\bigoplus \bigoplus \bigoplus \bigcirc \\
\text { MODERATE }^{\mathrm{a}}\end{array}$ & OR $1.21(0.60-2.43)$ & 6 per 1000 & $\begin{array}{l}1 \text { more per } 1000 \text { ( } 3 \text { fewer to } 9 \\
\text { more) }\end{array}$ \\
\hline Nervous system disorders & 2621 (4 RCTs) & $\begin{array}{l}\bigoplus \bigoplus \bigoplus \bigcirc \\
\text { MODERATE }^{\mathrm{a}}\end{array}$ & OR $0.60(0.41-0.88)$ & 25 per 1000 & $\begin{array}{l}10 \text { fewer per } 1000 \text { ( } 15 \text { fewer to } \\
3 \text { fewer) }\end{array}$ \\
\hline Serious adverse events & 2621 (4 RCTs) & $\begin{array}{l}\bigoplus \bigoplus \bigoplus \bigcirc \\
\text { MODERATE }^{\mathrm{a}}\end{array}$ & OR $0.63(0.23-1.72)$ & 10 per 1000 & $\begin{array}{l}4 \text { fewer per } 1000 \text { ( } 8 \text { fewer to } 7 \\
\text { more) }\end{array}$ \\
\hline
\end{tabular}

The risk in the intervention group (and its $95 \% \mathrm{CI}$ ) is based on the assumed risk in the comparison group and the relative effect of the intervention (and its $95 \% \mathrm{CI}$ )

GRADE Working Group grades of evidence: High certainty we are very confident that the true effect lies close to that of the estimate of the effect; Moderate certainty we are moderately confident in the effect estimate: the true effect is likely to be close to the estimate of the effect, but there is a possibility that it is substantially different; Low certainty our confidence in the effect estimate is limited: the true effect may be substantially different from the estimate of the effect; Very low certainty we have very little confidence in the effect estimate: the true effect is likely to be substantially different from the estimate of effect

$C I$ confidence interval, GRADE Grading of Recommendations Assessment, Development and Evaluation, $O R$ odds ratio, $R C T$ randomized controlled trials

${ }^{a}$ High risk of selective outcome reporting in all included studies. No data were provided by authors of manuscripts or sponsors of studies

the difference in odds versus placebo was not statistically significant (OR 1.73, 95\% CI 0.96-3.10).

Long-term safety profiles of oral NSAIDs are different from safety profiles of short-term use [55-57]. In this metaanalysis, the longest trial duration for the included studies was 12 weeks (Table 1). While there was no heterogeneity associated with the overall OR for withdrawal due to AEs $\left(I^{2}=0 \%\right)$ and total AEs $\left(I^{2}=0 \%\right)$ with topical diclofenac versus placebo, we undertook subgroup analyses in order to investigate any treatment- or study-related characteristic effects. Our investigation regarding the effect of treatment duration on the rate of total AEs and dropouts due to AEs with topical diclofenac versus placebo suggested an increase in AE rates over time, notably for total AEs (ESM 4). However, evidence from an open-label, long-term safety trial (daily application of topical diclofenac sodium $1 \%$ gel for 9-12 months) [58], and from a post hoc analysis of studies assessing the long-term tolerability (12 months) of the same treatment in patients with OA, concluded that longterm use of topical diclofenac was safe in these patients [59]. Therefore, the long-term safety of topical NSAIDs deserves further investigation.

Finally, we also investigated if there were differences in AE rates (total AEs and dropouts due to AEs) with topical diclofenac versus placebo, according to the localization of
OA, the type of topical formulation of the treatment and the daily dose, since these factors could influence the absorption and safety of topical treatments. Due to the very limited number of studies available for some subgroups (one to two studies) (ESM 4), we were unable to draw any definitive conclusion regarding these parameters. We would have also liked to compare the safety profile of topical diclofenac products containing dimethyl sulfoxide (DMSO) with that of the others, however none of the studies using topical diclofenac with DMSO were included in our analyses since they did not have adequate data for analysis (Table 1).

\subsection{Strengths}

Our meta-analysis included only RCTs of active treatment versus placebo, thus the real effect is not underestimated. Full safety data were obtained from the authors/sponsors of most of the studies, which allows for minimization of the risk of selective reporting bias. We reported on many SOCs, not only 'total AEs', 'serious AEs' or 'skin AEs', as in many of the previous meta-analyses. We avoided double counting of AEs. For each SOC, we considered the number of patients who experienced any related $\mathrm{AE}$ at least once, and, for total AEs (any AEs), we considered the number of patients who experienced any $\mathrm{AE}$ at least once during the study. 


\subsection{Limitations}

Many studies identified that met the inclusion criteria did not provide AE data suitable for inclusion in the meta-analysis, and the authors/sponsors did not provide us with the full safety data. For some other studies included in our analyses, mainly regarding topical ketoprofen and ibuprofen, only published data were available, which limited our conclusions regarding the safety profiles of these compounds.

There is a unit-of-analysis error issue in this meta-analysis, except for individual meta-analyses on topical diclofenac and topical ibuprofen. A unit-of-analysis problem arises when, in studies with multiple arms, the same group of participants is included twice in the same meta-analysis (for example, when 'dose 1 vs. placebo' and 'dose 2 vs. placebo' are both included in the same meta-analysis, with the same original number of placebo patients in both comparisons) [14]. The Cochrane handbook proposes various approaches to include multiple groups from a single study in the same meta-analysis. For the current meta-analysis, one of these proposed methods was suitable, consisting of splitting the 'shared' group into two or more groups with a smaller sample size, and including two or more comparisons. However, we decided not to apply this method as we found that it only marginally and not significantly altered our results and did not modify our conclusions. Additionally, we wanted to let each comparison (active vs. placebo), with its real effect estimate and $95 \% \mathrm{CI}$, as if we chose to select only one pair of interventions.

\section{Conclusions}

This meta-analysis demonstrates that topical NSAIDs may be considered safe for the management of pain in OA patients, with no specific AEs found to be significantly more frequent with topical treatment compared with placebo. In particular, topical NSAIDs are associated with low GI toxicity, and, in this respect, may be preferred over the use of oral NSAIDs. Increases in skin and subcutaneous disorders observed with topical treatment may be product-specific as notably higher rates were observed with diclofenac, although with no statistically significant difference to placebo. Although non-significant, an increase in cardiac disorders was observed across all topical NSAIDs (except with topical ibuprofen), which may require further investigation. While previously demonstrating small to moderate efficacy in providing pain relief in OA, our findings confirm that topical NSAIDs are an important component of the treatment armamentarium for OA, and may be considered as safe to use early on in the management algorithm. Nonetheless, the long-term safety profile of topical NSAIDs deserves further investigation. Therefore, the use of topical NSAIDs in OA should be considered, taking into account their risk: benefit profile in comparison with other anti-OA treatments.

Acknowledgements This paper was written on behalf of the European Society for Clinical and Economic Aspects of Osteoporosis, Osteoarthritis and Musculoskeletal Diseases (ESCEO) Working Group on the safety of anti-OA medications: Nasser Al-Daghri, Nigel Arden, Bernard Avouac, Olivier Bruyère, Roland Chapurlat, Philip Conaghan, Cyrus Cooper, Elizabeth Curtis, Elaine Dennison, Nicholas Fuggle, Gabriel Herrero-Beaumont, Germain Honvo, Margreet Kloppenburg, Stefania Maggi, Tim McAlindon, Alberto Migliore, Ouafa Mkinsi, François Rannou, Jean-Yves Reginster, René Rizzoli, Roland Roth, Thierry Thomas, Daniel Uebelhart, and Nicola Veronese. The authors of this article are grateful to the authors of the articles included in the meta-analysis and to the pharmaceutical companies who kindly accepted to collaborate with this project by sharing the raw safety data from these studies. The authors would also like to express their sincere gratitude to Laboratoires Genevrier (France) and GlaxoSmithKline (GSK, Switzerland), as well as to Doctor Ian Burnett (from Novartis Consumer Health SA-a GSK Consumer Healthcare company, Switzerland). They also thank Drs. Herbert S.B. Baraf, Stefano Rovati, Pius Brühlmann, Daniele Pavone, Alessandro Allegrini, Hakan Ergün, Gyula Varadi and Noboru Otsuka, as well as the sponsors of their studies, for having accepted to share their raw data with us. The authors acknowledge the assistance and advice of Nancy Durieux and Frédéric de Lemos Esteves from the Library of Life Sciences, University of Liège, Liège, Belgium, in the preparation of the search strategies for the systematic review, and thank them very sincerely for their contribution to one of the most important parts of this research. Finally, the authors would like to express their most sincere gratitude to $\mathrm{Dr}$ Lisa Buttle, $\mathrm{PhD}$, of Medscript Ltd, for her invaluable assistance with the manuscript preparation. Dr Lisa Buttle was entirely funded by the ESCEO asbl, Belgium.

\section{Compliance with Ethical Standards}

All authors meet the International Committee of Medical Journal Editors (ICMJE) criteria for authorship for this manuscript, take responsibility for the integrity of the work as a whole, and have given final approval of the version to be published.

Role of the Funding Source Germain Honvo was funded by the ESCEO, a Belgian not-for-profit organization, and the ESCEO Working Group was entirely funded by the ESCEO. The ESCEO receives unrestricted educational grants, to support its educational and scientific activities, from non-governmental organizations, not-for-profit organizations, and non-commercial and corporate partners. The choice of topics, participants, content and agenda of the working groups, as well as the writing, editing, submission and reviewing of the manuscript, are under the sole responsibility of the ESCEO, without any influence from third parties.

Conflict of Interest Olivier Bruyère reports grants from Biophytis, IBSA, MEDA, Servier, SMB and Theramex, outside of the submitted work. Cyrus Cooper reports personal fees from Alliance for Better Bone Health, Amgen, Eli Lilly, GlaxoSmithKline, Medtronic, Merck, Novartis, Pfizer, Roche, Servier, Takeda and UCB, outside of the submitted work. Jean-Yves Reginster reports grants from IBSA-Genevrier, Mylan, CNIEL and Radius Health (through institution); consulting fees from IBSA-Genevrier, Mylan, CNIEL, Radius Health and Pierre Fabre; fees for participation in review activities from IBSA-Genevrier, MYLAN, CNIEL, Radius Health and Teva; and payment for lectures from AgNovos, CERIN, CNIEL, Dairy Research Council (DRC), Echolight, IBSA-Genevrier, Mylan, Pfizer Consumer Health, Teva and 
Theramex, outside of the submitted work. Thierry Thomas reports personal fees from Abbvie, Amgen, Arrow, BMS, Chugai, Expanscience, Gilead, HAC-Pharma, LCA, Lilly, Medac, MSD, Pfizer, Thuasne, TEVA and UCB, and grants from Amgen, Bone Therapeutics, Chugai, HAC-Pharma, MSD, Novartis, Pfizer and UCB, outside of the submitted work. Germain Honvo, Nicola Veronese, Victoria Leclercq, Anton Geerinck, Alexia Charles, Charlotte Beaudart and Véronique Rabenda have no disclosures to report.

Open Access This article is distributed under the terms of the Creative Commons Attribution-NonCommercial 4.0 International License (http://creativecommons.org/licenses/by-nc/4.0/), which permits any noncommercial use, distribution, and reproduction in any medium, provided you give appropriate credit to the original author(s) and the source, provide a link to the Creative Commons license, and indicate if changes were made.

\section{References}

1. Bijlsma JW, Berenbaum F, Lafeber FP. Osteoarthritis: an update with relevance for clinical practice. Lancet. 2011;377(9783):211526. https://doi.org/10.1016/S0140-6736(11)60243-2.

2. Bruyere O, Cooper C, Pelletier JP, Branco J, Brandi ML, Guillemin F, et al. An algorithm recommendation for the management of knee osteoarthritis in Europe and internationally: a report from a task force of the European Society for Clinical and Economic Aspects of Osteoporosis and Osteoarthritis (ESCEO). Semin Arthritis Rheum. 2014;44(3):253-63. https://doi.org/10.1016/j. semarthrit.2014.05.014.

3. McAlindon TE, Bannuru RR, Sullivan MC, Arden NK, Berenbaum F, Bierma-Zeinstra SM, et al. OARSI guidelines for the non-surgical management of knee osteoarthritis. Osteoarthr Cartil. 2014;22(3):363-88. https://doi.org/10.1016/j.joca.2014.01.003.

4. Hochberg MC, Altman RD, April KT, Benkhalti M, Guyatt G, McGowan J, et al. American College of Rheumatology 2012 recommendations for the use of nonpharmacologic and pharmacologic therapies in osteoarthritis of the hand, hip, and knee. Arthritis Care Res. 2012;64(4):465-74. https://doi.org/10.1002/ acr.21596.

5. NICE. Osteoarthritis care and management in adults: methods, evidence and recommendations. National Clinical Guideline Centre. Report No. CG177. London: National Institute for Health and Care Excellence; 2014.

6. Jordan KM, Arden NK, Doherty M, Bannwarth B, Bijlsma JWJ, Dieppe P, et al. EULAR Recommendations 2003: an evidence based approach to the management of knee osteoarthritis: report of a Task Force of the Standing Committee for International Clinical Studies Including Therapeutic Trials (ESCISIT). Ann Rheum Dis. 2003;62(12):1145-55. https://doi.org/10.1136/ ard.2003.011742.

7. Zhang W, Nuki G, Moskowitz RW, Abramson S, Altman RD, Arden NK, et al. OARSI recommendations for the management of hip and knee osteoarthritis: part III: changes in evidence following systematic cumulative update of research published through January 2009. Osteoarthr Cartil. 2010;18(4):476-99. https://doi.org/10.1016/j.joca.2010.01.013.

8. Chou R, McDonagh MS, Nakamoto E, Griffin J. Analgesics for osteoarthritis: an update of the 2006 comparative effectiveness review. Comparative effectiveness review no. 38. October 2011. AHRQ Publication No. 11(12)-EHC076-EF. Rockville: Agency for Healthcare Research and Quality. http://www.ncbi.nlm.nih. gov/pubmedhealth/PMH0016485/pdf/TOC.pdf. Accessed 27 Apr 2018.
9. Makris UE, Kohler MJ, Fraenkel L. Adverse effects of topical nonsteroidal antiinflammatory drugs in older adults with osteoarthritis: a systematic literature review. J Rheumatol. 2010;37(6):1236-43. https://doi.org/10.3899/jrheum.090935.

10. Derry S, Conaghan P, Da Silva JA, Wiffen PJ, Moore RA. Topical NSAIDs for chronic musculoskeletal pain in adults. Cochrane Database Syst Rev. 2016;4:CD007400. https://doi. org/10.1002/14651858.cd007400.pub3.

11. Derry S, Moore RA, Rabbie R. Topical NSAIDs for chronic musculoskeletal pain in adults. Cochrane Database Syst Rev. 2012;9:CD007400. https://doi.org/10.1002/14651858.cd007 400.pub2.

12. Zou K, Wong J, Abdullah N, Chen X, Smith T, Doherty M, et al. Examination of overall treatment effect and the proportion attributable to contextual effect in osteoarthritis: metaanalysis of randomised controlled trials. Ann Rheum Dis. 2016;75(11):1964-70. https://doi.org/10.1136/annrheumdi s-2015-208387.

13. Zeng C, Wei J, Persson MSM, Sarmanova A, Doherty M, Xie D, et al. Relative efficacy and safety of topical non-steroidal antiinflammatory drugs for osteoarthritis: a systematic review and network meta-analysis of randomised controlled trials and observational studies. Br J Sports Med. 2018. https://doi.org/10.1136/ bjsports-2017-098043.

14. Higgins JPT, Green S. Cochrane handbook for systematic reviews of interventions. Version 5.1.0 (updated March 2011). The Cochrane Collaboration; 2011. http://www.handbook.cochrane. org. Accessed 19 July 2018.

15. Moher D, Liberati A, Tetzlaff J, Altman DG, Prisma Group. Preferred reporting items for systematic reviews and meta-analyses: the PRISMA statement. J Clin Epidemiol. 2009;62(10):1006-12. https://doi.org/10.1016/j.jclinepi.2009.06.005.

16. DerSimonian R, Laird N. Meta-analysis in clinical trials. Control Clin Trials. 1986;7(3):177-88.

17. Bradburn MJ, Deeks JJ, Berlin JA, Russell Localio A. Much ado about nothing: a comparison of the performance of meta-analytical methods with rare events. Stat Med. 2007;26(1):53-77. https ://doi.org/10.1002/sim.2528.

18. Stijnen T, Hamza TH, Ozdemir P. Random effects meta-analysis of event outcome in the framework of the generalized linear mixed model with applications in sparse data. Stat Med. 2010;29(29):3046-67. https://doi.org/10.1002/sim.4040.

19. Normand SL. Meta-analysis: formulating, evaluating, combining, and reporting. Stat Med. 1999;18(3):321-59.

20. Higgins JP, Thompson SG, Deeks JJ, Altman DG. Measuring inconsistency in meta-analyses. BMJ. 2003;327(7414):557-60. https://doi.org/10.1136/bmj.327.7414.557.

21. Harbord RM, Egger M, Sterne JA. A modified test for smallstudy effects in meta-analyses of controlled trials with binary endpoints. Stat Med. 2006;25(20):3443-57. https://doi. org/10.1002/sim.2380.

22. Sterne JA, Sutton AJ, Ioannidis JP, Terrin N, Jones DR, Lau J, et al. Recommendations for examining and interpreting funnel plot asymmetry in meta-analyses of randomised controlled trials. BMJ. 2011;343:d4002. https://doi.org/10.1136/bmj.d4002.

23. Egger M, Davey Smith G, Schneider M, Minder C. Bias in meta-analysis detected by a simple, graphical test. BMJ. 1997;315(7109):629-34.

24. Guyatt G, Oxman AD, Akl EA, Kunz R, Vist G, Brozek J, et al. GRADE guidelines: 1. Introduction-GRADE evidence profiles and summary of findings tables. J Clin Epidemiol. 2011;64(4):383-94. https://doi.org/10.1016/j.jclin epi.2010.04.026.

25. GRADEpro GDT: GRADEpro Guideline Development Tool [Software]. McMaster University, 2015 (developed by Evidence Prime, Inc.). Available from gradepro.org. Evidence Prime, Inc. 
26. Barthel HR, Peniston JH, Clark MB, Gold MS, Altman RD. Correlation of pain relief with physical function in hand osteoarthritis: randomized controlled trial post hoc analysis. Arthritis Res Ther. 2010;12(1):R7. https://doi.org/10.1186/ar2906.

27. Baraf HS, Gloth FM, Barthel HR, Gold MS, Altman RD. Safety and efficacy of topical diclofenac sodium gel for knee osteoarthritis in elderly and younger patients: pooled data from three randomized, double-blind, parallel-group, placebo-controlled, multicentre trials. Drugs Aging. 2011;28(1):27-40. https://doi. org/10.2165/11584880-000000000-00000.

28. Allegrini A, Nuzzo L, Pavone D, Tavella-Scaringi A, Giangreco D, Bucci M, et al. Efficacy and safety of piroxicam patch versus piroxicam cream in patients with lumbar osteoarthritis. A randomized, placebo-controlled study. Arzneimittelforschung. 2009;59(8):403-9.

29. Altman RD, Dreiser RL, Fisher CL, Chase WF, Dreher DS, Zacher J. Diclofenac sodium gel in patients with primary hand osteoarthritis: a randomized, double-blind, placebo-controlled trial. J Rheumatol. 2009;36(9):1991-9. https://doi.org/10.3899/ jrheum.081316.

30. Baer PA, Thomas LM, Shainhouse Z. Treatment of osteoarthritis of the knee with a topical diclofenac solution: a randomised controlled, 6-week trial [ISRCTN53366886]. BMC Musculoskelet Disord. 2005;6:44. https://doi.org/10.1186/1471-2474-6-44.

31. Baraf HS, Gold MS, Clark MB, Altman RD. Safety and efficacy of topical diclofenac sodium $1 \%$ gel in knee osteoarthritis: a randomized controlled trial. Phys Sportsmed. 2010;38(2):19.

32. Barthel HR, Haselwood D, Longley S, Gold MS, Altman RD. Randomized controlled trial of diclofenac sodium gel in knee osteoarthritis. Semin Arthritis Rheum. 2009;39(3):203.

33. Bookman AA, Williams KS, Shainhouse JZ. Effect of a topical diclofenac solution for relieving symptoms of primary osteoarthritis of the knee: a randomized controlled trial. CMAJ. 2004;171(4):333-8. https://doi.org/10.1503/cmaj.1031793.

34. Bruhlmann P, Michel BA. Topical diclofenac patch in patients with knee osteoarthritis: a randomized, double-blind, controlled clinical trial. Clin Exp Rheumatol. 2003;21(2):193-8.

35. Conaghan PG, Dickson J, Bolten W, Cevc G, Rother M. A multicentre, randomized, placebo- and active-controlled trial comparing the efficacy and safety of topical ketoprofen in Transfersome gel (IDEA-033) with ketoprofen-free vehicle (TDT 064) and oral celecoxib for knee pain associated with osteoarthritis. Rheumatology (Oxf). 2013;52(7):1303-12. https://doi.org/10.1093/rheum atology/ket133.

36. Dreiser RL, Tisne-Camus M. DHEP plasters as a topical treatment of knee osteoarthritis - a double-blind placebo-controlled study. Drugs Exp Clin Res. 1993;19(3):117.

37. Ergun H, Kulcu D, Kutlay S, Bodur H, Tulunay FC. Efficacy and safety of topical nimesulide in the treatment of knee osteoarthritis. J Clin Rheumatol. 2007;13(5):251.

38. Grace D, Rogers J, Skeith K, Anderson K. Topical diclofenac versus placebo: a double blind, randomized clinical trial in patients with osteoarthritis of the knee. J Rheumatol. 1999;26(12):2659.

39. Kneer W, Rother M, Mazgareanu S, Seidel EJ, European IdeaStudy Group. A 12-week randomized study of topical therapy with three dosages of ketoprofen in Transfersome gel (IDEA-033) compared with the ketoprofen-free vehicle (TDT 064), in patients with osteoarthritis of the knee. J Pain Res. 2013;6(101540514):743-53. https://doi.org/10.2147/JPR.S51054.

40. Niethard F, Gold MS, Solomon GS, Liu JM, Unkauf M, Albrecht $\mathrm{HH}$, et al. Efficacy of topical diclofenac diethylamine gel in osteoarthritis of the knee. J Rheumatol. 2005;32(12):2384.

41. Ottillinger B, Gomor B, Michel BA, Pavelka K, Beck W, Elsasser $\mathrm{U}$. Efficacy and safety of eltenac gel in the treatment of knee osteoarthritis. Osteoarthr Cartil. 2001;9(3):273-80. https://doi. org/10.1053/joca.2000.0385.
42. Roth SH, Shainhouse JZ. Efficacy and safety of a topical diclofenac solution (pennsaid) in the treatment of primary osteoarthritis of the knee: a randomized, double-blind, vehicle-controlled clinical trial. Arch Intern Med. 2004;164(18):2017-23.

43. Rother M, Conaghan PG. A randomized, double-blind, phase III trial in moderate osteoarthritis knee pain comparing topical ketoprofen gel with ketoprofen-free gel. J Rheumatol. 2013;40(10):1742-8. https://doi.org/10.3899/jrheum.130192.

44. Rother M, Lavins BJ, Kneer W, Lehnhardt K, Seidel EJ, Mazgareanu S. Efficacy and safety of epicutaneous ketoprofen in Transfersome (IDEA-033) versus oral celecoxib and placebo in osteoarthritis of the knee: multicentre randomised controlled trial. Ann Rheum Dis. 2007;66(9):1178-83. https://doi.org/10.1136/ ard.2006.065128.

45. Rovensky J, Micekova D, Gubzova Z, Fimmers R, Lenhard G, Vogtle-Junkert U, et al. Treatment of knee osteoarthritis with a topical non-steroidal antiinflammatory drug. Results of a randomized, double-blind, placebo-controlled study on the efficacy and safety of a 5\% ibuprofen cream. Drugs Exp Clin Res. 2001;27(5-6):209.

46. Sandelin J, Harilainen A, Crone H, Hamberg P, Forsskahl B, Tamelander G. Local NSAID gel (eltenac) in the treatment of osteoarthritis of the knee. A double blind study comparing eltenac with oral diclofenac and placebo gel. Scand J Rheumatol. 1997;26(4):287.

47. Trnavsky K, Fischer M, Vogtle-Junkert U, Schreyger F. Efficacy and safety of 5\% ibuprofen cream treatment in knee osteoarthritis. Results of a randomized, double-blind, placebo-controlled study. J Rheumatol. 2004;31(3):565.

48. Varadi G, Zhu Z, Blattler T, Hosle M, Loher A, Pokorny R, et al. Randomized clinical trial evaluating transdermal ibuprofen for moderate to severe knee osteoarthritis. Pain Phys. 2013;16(6):E749.

49. Wadsworth LT, Kent JD, Holt RJ. Efficacy and safety of diclofenac sodium 2\% topical solution for osteoarthritis of the knee: a randomized, double-blind, vehicle-controlled, 4 week study. Curr Med Res Opin. 2016;32(2):241.

50. Yataba I, Otsuka N, Matsushita I, Matsumoto H, Hoshino Y. The efficacy and safety of s-flurbiprofen plaster in the treatment of knee osteoarthritis: a phase II, randomized, double-blind, placebocontrolled, dose-finding study. Mod Rheumatol. 2017;10:867.

51. Lin J, Zhang W, Jones A, Doherty M. Efficacy of topical nonsteroidal anti-inflammatory drugs in the treatment of osteoarthritis: meta-analysis of randomised controlled trials. BMJ. 2004;329(7461):324. https://doi.org/10.1136/bmj.38159.63902 $8.7 \mathrm{C}$.

52. Heyneman CA, Lawless-Liday C, Wall GC. Oral versus topical NSAIDs in rheumatic diseases: a comparison. Drugs. 2000;60(3):555-74.

53. Deng ZH, Zeng C, Yang Y, Li YS, Wei J, Yang T, et al. Topical diclofenac therapy for osteoarthritis: a meta-analysis of randomized controlled trials. Clin Rheumatol. 2016;35(5):1253-61. https://doi.org/10.1007/s10067-015-3021-z.

54. Sardana V, Burzynski J, Zalzal P. Safety and efficacy of topical ketoprofen in transfersome gel in knee osteoarthritis: a systematic review. Musculoskelet Care. 2017;15(2):114-21. https://doi. org/10.1002/msc. 1163.

55. De Caterina R, Ruigomez A, Rodriguez LA. Long-term use of anti-inflammatory drugs and risk of atrial fibrillation. Arch Intern Med. 2010;170(16):1450-5. https://doi.org/10.1001/archintern med.2010.305.

56. Garcia Rodriguez LA, Gonzalez-Perez A. Long-term use of nonsteroidal anti-inflammatory drugs and the risk of myocardial infarction in the general population. BMC Med. 2005;3:17. https ://doi.org/10.1186/1741-7015-3-17. 
57. Marcum ZA, Hanlon JT. Recognizing the risks of chronic nonsteroidal anti-inflammatory drug use in older adults. Ann Longterm Care. 2010;18(9):24-7.

58. Peniston JH, Gold MS, Alwine LK. An open-label, long-term safety and tolerability trial of diclofenac sodium $1 \%$ gel in patients with knee osteoarthritis. Phys Sportsmed. 2011;39(3):31-8. https://doi.org/10.3810/psm.2011.09.1918.
59. Peniston JH, Gold MS, Wieman MS, Alwine LK. Long-term tolerability of topical diclofenac sodium $1 \%$ gel for osteoarthritis in seniors and patients with comorbidities. Clin Interv Aging. 2012;7:517-23. https://doi.org/10.2147/CIA.S35416.

\section{Affiliations}

\section{Germain Honvo $^{1,2}\left(\mathbb{D}^{-} \cdot\right.$ Victoria Leclercq $^{1,2} \cdot$ Anton Geerinck $^{1,2} \cdot$ Thierry Thomas $^{3} \cdot$ Nicola Veronese $^{4} \cdot$ Alexia Charles $^{1,2}$. Véronique Rabenda $^{1,2} \cdot$ Charlotte Beaudart ${ }^{1,2} \cdot$ Cyrus Cooper $^{2,5,6}$. Jean-Yves Reginster ${ }^{1,2,7}$ (i) Olivier Bruyère ${ }^{1,2}$ (i)}

Victoria Leclercq

victoria.leclercq@uliege.be

Anton Geerinck

anton.geerinck@uliege.be

Thierry Thomas

thierry.thomas@chu-st-etienne.fr

Nicola Veronese

ilmannato@gmail.com

Alexia Charles

alexia.charles@uliege.be

Véronique Rabenda

veronique.rabenda@uliege.be

Charlotte Beaudart

c.beaudart@uliege.be

Cyrus Cooper

cc@mrc.soton.ac.uk

Jean-Yves Reginster

jyreginster@uliege.be

Olivier Bruyère

olivier.bruyere@uliege.be
1 Department of Public Health, Epidemiology and Health Economics, University of Liège, Liège, Belgium

2 WHO Collaborating Centre for Public Heath Aspects of Musculoskeletal Health and Aging, Liège, Belgium

3 Department of Rheumatology, Hôpital Nord, CHU de St-Etienne and INSERM 1059, Université de Lyon, Saint-Étienne, France

4 National Research Council, Neuroscience Institute, Aging Branch, Padua, Italy

5 MRC Lifecourse Epidemiology Unit, Southampton General Hospital, University of Southampton, Southampton, UK

6 Musculoskeletal Biomedical Research Unit, National Institute for Health Research (NIHR), University of Oxford, Oxford, UK

7 Chair for Biomarkers of Chronic Diseases, Biochemistry Department, College of Science, King Saud University, Riyadh, Kingdom of Saudi Arabia 